\title{
Proteoglycan 4 Reduces Neuroinflammation and Protects the Blood-Brain Barrier after Traumatic Brain Injury
}

\author{
Marissa Bennett, ${ }^{1}$ Andrea Chin,, Hyung Jin Lee, ${ }^{1}$ Emma Morales Cestero, ${ }^{2}$ Nathalie Strazielle, ${ }^{3}$ \\ Jean-François Ghersi-Egea, ${ }^{4}$ Steven W. Threlkeld, ${ }^{2}$ Tannin A. Schmidt, ${ }^{5}$ Holly A. Richendrfer, ${ }^{6}$ \\ Joanna Szmydynger-Chodobska, ${ }^{1}$ Gregory D. Jay, ${ }^{6}$ and Adam Chodobski ${ }^{1}$
}

\begin{abstract}
Neuroinflammation and dysfunction of the blood-brain barrier (BBB) are two prominent mechanisms of secondary injury in neurotrauma. It has been suggested that Toll-like receptors (TLRs) play important roles in initiating and propagating neuroinflammation resulting from traumatic brain injury (TBI), but potential beneficial effects of targeting these receptors in TBI have not been broadly studied. Here, we investigated the effect of targeting TLRs with proteoglycan 4 (PRG4) on post-traumatic neuroinflammation and BBB function. PRG4 is a mucinous glycoprotein with strong anti-inflammatory properties, exerting its biological effects by interfering with TLR2/4 signaling. In addition, PRG4 has the ability to inhibit activation of cluster of differentiation 44 (CD44), a cell-surface glycoprotein playing an important role in inflammation. Using the controlled cortical impact model of TBI in rats, we showed a rapid and prolonged upregulation of message for TLR2/4 and CD44 in the injured cortex. In the in vitro model of the BBB, recombinant human PRG4 (rhPRG4) crossed the endothelial monolayers through a high-capacity, saturable transport system. In rats sustaining TBI, PRG4 delivery to the brain was enhanced by post-traumatic increase in BBB permeability. rhPRG4 injected intravenously at $1 \mathrm{~h}$ post-TBI potently inhibited post-traumatic activation of nuclear factor kappa B and extracellular signal-regulated kinases $1 / 2$, the two major signal transduction pathways associated with TLR2/4 and CD44, and curtailed the post-traumatic influx of monocytes. In addition, PRG4 restored normal BBB function after TBI by preventing the post-traumatic loss of tight junction protein claudin 5 and reduced neuronal death. Our observations provide support for therapeutic strategies targeting TLRs in TBI.
\end{abstract}

Keywords: blood-brain barrier; CD44; neuroinflammation; proteoglycan 4; Toll-like receptors

\section{Introduction}

$\mathbf{T}$ RAUMATIC BRAIN INJURY (TBI) has a significant health and socioeconomic impact on societies in both developed and developing countries. Repetitive TBI or even a single incident of brain injury may, in the long run, result in progressive neurodegeneration, ${ }^{1}$ and it has been suggested that TBI is a risk factor for Alzheimer's disease-like dementia. ${ }^{2}$ The pathophysiology of TBI is complex, and in patients who survived the initial trauma, morbidity and mortality largely depend on the severity of secondary injury.
Neuroinflammation is one of the mechanisms of secondary injury in TBI, and increasing evidence indicates that posttraumatic neuroinflammation significantly contributes to neuronal death observed after neurotrauma. ${ }^{3}$ Neuroinflammation also has a detrimental effect on neurogenesis and memory retention, and plays a role in the pathophysiology of depressive disorders, ${ }^{4-8}$ all of which affect the long-term neurological outcome after TBI. Although triggered relatively quickly after injury, post-traumatic neuroinflammation appears to progress at a slower pace compared to other secondary injury mechanisms, such as glutamate excitotoxicity, which is caused by a rapid (within minutes post-TBI)

\footnotetext{
${ }^{1}$ Neurotrauma and Brain Barriers Research Laboratory, ${ }^{6}$ Department of Emergency Medicine, Alpert Medical School of Brown University, Providence, Rhode Island, USA.

${ }^{2}$ Department of Neuroscience, Regis College, Weston, Massachusetts, USA.

${ }^{3}$ Brain-i, Lyon, France.

${ }^{4}$ FLUID Team and BIP Facility, Lyon Neuroscience Research Center, INSERM U1028, CNRS UMR5292, Lyon 1 University, Lyon, France.

${ }^{5}$ Department of Biomedical Engineering, University of Connecticut Health Center, Farmington, Connecticut, USA.

(c) Marissa Bennett et al., 2020; Published by Mary Ann Liebert, Inc. This Open Access article is distributed under the terms of the Creative Commons Attribution Noncommercial License (http://creativecommons.org/licenses/by-nc/4.0/) which permits any noncommercial use, distribution, and reproduction in any medium, provided the original author(s) and the source are credited.
} 
and short-lasting increase in extracellular levels of glutamate. ${ }^{9,10}$ Therefore, neuroinflammation could potentially be targeted therapeutically within the time frame that is applicable to the reality of clinical settings.

Post-traumatic neuroinflammation is characterized by increased production of proinflammatory mediators, such as proinflammatory cytokines and chemokines, followed by the influx of inflammatory cells, predominantly neutrophils and monocytes. ${ }^{3}$ It is important to note that, unlike neutrophils, monocytes, which enter the injured brain with a 24-h delay, continue to invade the brain parenchyma for a prolonged period of time after TBI. ${ }^{11}$ The post-traumatic influx of monocytes has a detrimental effect on neuronal survival and functional outcome after TBI. ${ }^{12-15}$ There is also evidence, obtained from rodent and human studies, for persistent posttraumatic activation of microglia, lasting for months to years after $\mathrm{TBI},{ }^{16-18}$ which is likely to contribute to neurodegenerative processes occurring in the injured brain. ${ }^{19,20}$ What is still not well understood is how post-traumatic neuroinflammation is initiated.

The available data suggest that Toll-like receptors (TLRs), especially TLR2 and TLR4, play important roles in initiating and sustaining neuroinflammation in the injured brain. It is now well established that TLRs not only recognize pathogen-associated molecular patterns, such as lipopolysaccharide (LPS), but are also activated by the so-called damage-associated molecular patterns (DAMPs), the endogenous molecules released and/or generated in the brain after injury. ${ }^{3}$ Brain levels of multiple DAMPs, including high mobility group box 1 (HMGB1), galectin 3 (LGALS3), and tenascin $\mathrm{C}$ (TNC), as well as the low-molecular-weight fragments of hyaluronic acid (HA), all of which are TLR2/4 ligands, ${ }^{21}$ have been found to be elevated after injury. ${ }^{22-25}$

One of the hallmarks of secondary injury in TBI is a rapid increase in permeability of the blood-brain barrier (BBB). With the leaky BBB, plasma proteins, such as fibrinogen, thrombin, and albumin, which are normally excluded from the brain, are able to enter the injured brain parenchyma, triggering neuroinflammation and accelerating neuronal death. ${ }^{3}$ Some of these blood-borne proteins, like fibrinogen, may also activate TLRs. ${ }^{21}$ Accordingly, reducing the post-traumatic leakiness of the BBB should be one of the goals of effective therapy for TBI.

The objective of this study was to investigate how targeting of TLR2/4 with recombinant human (rhPRG4) proteoglycan 4 (PRG4) affects post-traumatic neuroinflammation and neuronal death after TBI. Initially identified as lubricin, PRG4 is a mucinous glycoprotein best known for its ability to protect articular cartilage by acting as a lubricant. ${ }^{26}$ However, it has been shown that PRG4 also possesses strong anti-inflammatory ${ }^{27,28}$ and -adhesive properties. ${ }^{29,30}$ PRG4 exerts its anti-inflammatory effects by binding to TLR2 and TLR4, and interfering with their signaling. ${ }^{31,32}$ In addition to its inhibitory effect on TLR2/4 signaling, PRG4 competes with HA for binding to cluster of differentiation 44 (CD44), ${ }^{33,34}$ a cell-surface glycoprotein playing an important role in inflammation. ${ }^{35}$ Thus, PRG4 may inhibit the post-traumatic activation of both TLR2/4 and CD44 in response to proinflammatory lowmolecular-weight fragments of $\mathrm{HA},{ }^{36}$ which are generated in the injured brain. ${ }^{25}$

In the course of these investigations, we found that PRG4 reduces the influx of monocytes to the injured brain, which is consistent with its ability to inhibit activation of TLR2/4 and CD44. We also show that PRG4 acts to restore normal BBB function after TBI by preventing the post-traumatic loss of tight junction (TJ) protein claudin 5 (CLDN5), and that it exerts a neuroprotective effect in neurotrauma.

\section{Methods}

\section{Reagents and antibodies}

SuperScript IV reverse transcriptase, RNase inhibitor RNaseOut, and 70-kDa fluorescein-conjugated dextran (anionic) were obtained from ThermoFisherScientific (Waltham, MA). HotStart Taq DNA polymerase was purchased from Qiagen (Valencia, CA). Low-endotoxin bovine serum albumin (BSA) was from Millipore (Billerica, MA), and ultrapure LPS from Escherichia coli K12 strain was from Invivogen (San Diego, CA). ${ }^{14} \mathrm{C}$-sucrose $(350 \mathrm{mCi} / \mathrm{mmol})$ was from Amersham (Little Chalfont, UK).

For enzyme-linked immunosorbent assay (ELISA), the following antibodies were used: goat polyclonal antifluorescein antibody (NB600-1273; $1 \mu \mathrm{g} / \mathrm{mL}$ ) from Novus Biologicals (Littleton, CO) as the capture antibody and biotinylated goat polyclonal antifluorescein antibody (GTX26655; $50 \mathrm{ng} / \mathrm{mL}$ ) from GeneTex (Irvine, CA) as the detection antibody.

For western blotting, the following antibodies were used: rabbit monoclonal antihuman phosphorylated (p)-IKK $\alpha / \beta(\mathrm{I} \kappa \mathrm{B}$ kinase $\alpha /$ $\beta$; Ser176/Ser180 [2697; clone 16A6, diluted 1:100; from Cell Signaling Technology, Danvers, MA]); rabbit polyclonal antihuman IKK $\alpha / \beta$ (orb157675; $1.25 \mu \mathrm{g} / \mathrm{mL}$ ) from Biorbyt (Cambridge, UK); rabbit polyclonal antihuman p-ERK1/2 (extracellular signalregulated kinases 1/2; Thr202/Tyr204; [9101; diluted 1:1000; from Cell Signaling Technology]); rabbit polyclonal antirat ERK1/2 (9102; diluted 1:2000; from Cell Signaling Technology); mouse monoclonal antirat cluster of differentiation 68 (CD68; MCA341R; clone ED1, $1 \mu \mathrm{g} / \mathrm{mL}$; from Serotec, Oxford, UK); mouse monoclonal antimouse claudin 5 (CLDN5; 35-2500; clone 4C3C2, $0.25 \mu \mathrm{g} / \mathrm{mL}$; from ThermoFisherScientific); mouse monoclonal antihuman $\beta$-actin (3700; clone 8H10D10, diluted 1:10,000; from Cell Signaling Technology); and goat polyclonal antirat albumin (55710; $0.4 \mu \mathrm{g} / \mathrm{mL}$; from MP Biomedicals, Irvine, CA). For western blot detection, horseradish peroxidase-conjugated antirabbit and -mouse immunoglobulin G (IgG) antibodies (7074 and 7076, respectively; diluted 1:5000; from Cell Signaling Technology) or antigoat IgG antibody (sc-2354; $40 \mathrm{ng} / \mathrm{mL}$; from Santa Cruz Biotechnology, Santa Cruz, CA) were used.

\section{Labeling of recombinant human proteoglycan 4}

Full-length (1404 amino acids) rhPRG4 was obtained from Lubris (Framingham, MA). For studies of PRG4 transport across the BBB, rhPRG4 was labeled with fluorescein isothiocyanate (FITC), using the FluoReporter FITC Protein Labeling Kit from ThermoFisherScientific. FITC-labeled rhPRG4 (rhPRG4-FITC) was purified using spin columns provided by the manufacturer. rhPRG4-FITC preparations were run on sodium dodecyl sulfate (SDS)/polyacrylamide gels (4-12\%) under non-reducing conditions, and the gels were analyzed using the Bio-Rad (Hercules, CA) Gel Documentation System. This analysis showed that the labeling process did not affect the integrity of rhPRG4 molecules, and no free FITC was found in rhPRG4-FITC preparations used in this study (Supplementary Fig. S1A).

\section{The assessment of biological activity of fluorescein isothiocyanate-labeled recombinant human proteoglycan 4}

The biological activity of rhPRG4-FITC was examined using human brain endothelial cell line hCMEC/D3. ${ }^{37}$ These cells were provided by Dr. Pierre-Olivier Couraud (INSERM U1016, Institut Cochin, Paris, France). The hCMEC/D3 cells at passage 29 were grown in CytoOne multi-well plates (USA Scientific, Ocala, FL) in EGM-2 BulletKit medium (Lonza, Alpharetta, GA) containing 2\% fetal bovine serum, $0.04 \%$ hydrocortisone, $0.4 \%$ fibroblast growth factor $2,0.1 \%$ vascular endothelial growth factor A, $0.1 \%$ R3 
insulin-like growth factor $1,0.1 \%$ ascorbic acid, $0.1 \%$ heparin, and $0.1 \%$ gentamicin/amphotericin $\mathrm{B}$ at $37^{\circ} \mathrm{C}$ in a humidified atmosphere of $5 \% \mathrm{CO}_{2} / 95 \%$ air. Cells were exposed to $100 \mathrm{ng} / \mathrm{mL}$ of LPS for $30 \mathrm{~min}$ before treatment with rhPRG4 or rhPRG4-FITC $(150 \mu \mathrm{g} / \mathrm{mL}$ ) for $23.5 \mathrm{~h}$. Levels of interleukin-6 (IL-6) in the cellculture media were measured using a SimpleStep Human IL-6 ELISA Kit from Abcam (Cambridge, MA).

\section{The rat model of traumatic brain injury}

Adult male Long-Evans rats, weighing 250-275 g (Harlan, Indianapolis, IN), were kept at $22^{\circ} \mathrm{C}$ with a 12 -h light cycle and maintained on standard pellet rat chow and water ad libitum. The surgical and animal care procedures used in this study conformed to the National Institutes of Health (NIH) Guide for the Care and Use of Laboratory Animals (NIH Publication No. 8023, revised 1978) and were approved by the Animal Care and Use Committee of Rhode Island Hospital. Four to 6 rats per group/time point were used for most experiments, with the exception of studies in which the effect of PRG4 on post-traumatic neuronal death was evaluated ( $n=12$ rats per group) and when the permeability of the BBB to PRG4 in rats sustaining TBI was measured ( $n=3$ rats per group). The controlled cortical impact model of TBI was used as previously described. ${ }^{38}$ In brief, rats were anesthetized with intraperitoneal (i.p.) pentobarbital sodium $(60 \mathrm{mg} / \mathrm{kg})$, and a $4-\mathrm{mm}$ craniotomy was performed on the right side of the skull to expose the dura with the center of the opening located $3 \mathrm{~mm}$ posterior to the bregma and $2.5 \mathrm{~mm}$ lateral to the midline. Velocity of impact was $5 \mathrm{~m} / \mathrm{sec}$, and the duration of impact was $50 \mathrm{msec}$. The diameter of the impactor tip was $2.5 \mathrm{~mm}$, and the depth of brain deformation was set at $3 \mathrm{~mm}$. Animals were injected intravenously (i.v.; through the penis vein) with rhPRG4 $(1,2.5$, or $5 \mathrm{mg} / \mathrm{kg})$ or vehicle $(0.9 \% \mathrm{NaCl})$ at $1 \mathrm{~h}$ post-TBI.

\section{The in vitro model of the blood-brain barrier and the transport of proteoglycan 4 across brain endothelial monolayers}

The in vitro $\mathrm{BBB}$ model was based on primary cultures of rat brain endothelial cells. These cells were isolated from cerebral cortices of male or female 5-week-old Sprague-Dawley rats (Janvier Labs, Le Genest-Saint-Isle, France) and were cultured in Dulbecco's modified Eagle's medium (DMEM)/F12 medium as previously described. ${ }^{39}$ The animal procedures used in this study conformed to the EU Directive 2010/63/EU for animal experiments and were approved by the Animal Care and Use Committee at the Lyon Neurosciences Research Center.

To measure the transfer of PRG4 across endothelial monolayers, brain endothelial cells were plated in quadruplicate on Transwell polycarbonate membranes (pore size, $0.4 \mu \mathrm{m}$; cell growth area, $1.12 \mathrm{~cm}^{2}$ ) from Costar (Corning Life Sciences, Hazebrouck, France).

We first determined whether PRG4 has an effect on the integrity of endothelial monolayers. To this end, the flux of ${ }^{14} \mathrm{C}$ sucrose, a paracellular permeability marker, across endothelial monolayers was measured. ${ }^{40}$ rhPRG4 in DMEM/F12 medium containing $0.1 \%$ BSA was added to the blood (luminal) compartment at the concentration of 15,150 , or $1200 \mu \mathrm{g} / \mathrm{mL}$, and cells were incubated for $2 \mathrm{~h}$. Control cells (without rhPRG4) were treated in a similar manner. The flux of ${ }^{14} \mathrm{C}$-sucrose was measured during the last $20 \mathrm{~min}$ of the incubation period. Samples from the acceptor and donor compartments were analyzed for the content of ${ }^{14} \mathrm{C}$-sucrose by liquid scintillation counting, and the permeability coefficient for sucrose $(\mathrm{Pe})$ was calculated as previously described. ${ }^{40}$

Transfer of PRG4 across endothelial monolayers and its putative saturability were evaluated in the luminal-to-abluminal direction. rhPRG4-FITC was added to the culture media to achieve the concentration of 15 or $150 \mu \mathrm{g} / \mathrm{mL}$, or was mixed with unlabeled rhPRG4 in the $1: 8$ proportion, so that the final concentration of total rhPRG4 amounted to $1200 \mu \mathrm{g} / \mathrm{mL}$. Cells were incubated for 2 and $3.5 \mathrm{~h}$, and concentrations of rhPRG4-FITC were measured in the acceptor and donor compartments. Clearance curves across the cell-filter system were generated as previously described. ${ }^{40}$

\section{Measurement of blood-brain barrier permeability to proteoglycan 4 in injured rats}

For the BBB permeability studies, rats had their femoral vein and artery cannulated at one side of the body for the tracer/marker injection and collection of serial blood samples, respectively. This was completed shortly before the time point post-TBI (4$24 \mathrm{~h}$ ) at which the permeability measurements were done and required additional anesthesia (i.p. pentobarbital sodium). We first measured the permeability of the BBB to fluoresceinconjugated dextran of $70 \mathrm{kDa}$, at 4,6 , and $24 \mathrm{~h}$ post-TBI. Dextran (70-kDa) was injected i.v. at $2 \mathrm{mg} / \mathrm{kg}$ and was allowed to circulate for $30 \mathrm{~min}$. Serial arterial blood samples were collected at 1 , $3,5,10,15,20$, and $30 \mathrm{~min}$ after injection, and plasma was isolated by centrifugation. At the end of a 30-min circulation period, the marker was washed from the vasculature by transcardial perfusion with $200 \mathrm{~mL}$ of ice-cold $0.9 \% \mathrm{NaCl}$. This effectively removed the residual marker from brain vasculature, as judged by undetectable levels of $70-\mathrm{kDa}$ dextran in cortical samples collected from uninjured rats that underwent the same procedures. BBB permeability to PRG4 was measured at 4 and $24 \mathrm{~h}$ post-TBI. rhPRG4-FITC was injected i.v. at $3 \mathrm{mg} / \mathrm{kg}$ and was allowed to circulate for $40 \mathrm{~min}$. Arterial blood samples were collected as described for 70-kDa dextran with additional sample being collected at $40 \mathrm{~min}$ after rhPRG4-FITC injection.

After the transcardial perfusion with ice-cold $0.9 \% \mathrm{NaCl}$, cortical and hippocampal samples were quickly collected, weighed, homogenized in 10 volumes of 1\% Triton X-100 (Sigma-Aldrich, St. Louis, MO) in 50-mM phosphate-buffered saline (PBS) and centrifuged to obtain supernatant for further analysis. Plasma data were fit to the biexponential equations using a nonlinear regression analysis (SigmaPlot software; Systat Software, Inc., San Jose, CA). The BBB permeability surface area product (PS) for PRG4 and $70-\mathrm{kDa}$ dextran was calculated as previously described. ${ }^{41}$

\section{The assessment of recombinant human proteoglycan 4 stability in injured rats}

To evaluate the short-term stability of rhPRG4 in the injured cortex and plasma, rhPRG4-FITC was injected i.v. $(3 \mathrm{mg} / \mathrm{kg})$ at 4 or $24 \mathrm{~h}$ post-TBI, and $40 \mathrm{~min}$ later rats were perfused transcardially with $200 \mathrm{~mL}$ of ice-cold $0.9 \% \mathrm{NaCl}$. Samples of the ipsilateral cortex were collected and processed using isotonic lysis buffer (see below). Blood samples were collected before initiating the transcardial perfusion and plasma was isolated by centrifugation. For comparison, rhPRG4-FITC was also administered to intact animals. To examine the long-term stability of rhPRG4, rats were injected i.v. with rhPRG4-FITC $(3 \mathrm{mg} / \mathrm{kg})$ at $4 \mathrm{~h}$ post-TBI and were euthanized at 24 or $48 \mathrm{~h}$ after injury. Two rats per group/time point were used. Cortical and plasma samples were run on the SDS/polyacrylamide gels (4-12\%) under non-reducing conditions, and the gels were analyzed using the Bio-Rad Gel Documentation System.

\section{Enzyme-linked immunosorbent assay}

Concentrations of rhPRG4-FITC and fluorescein-conjugated dextran of $70 \mathrm{kDa}$ were measured using fluorescein/FITC sandwich ELISA developed by our group. In brief, 96-well microplates were first coated (overnight) with the capture antifluorescein goat antibody. After blocking with $1 \% \mathrm{BSA}$ at room temperature 
(45 min) and incubation ( $1 \mathrm{~h}$ ) with appropriately diluted samples, microplates were incubated for $1 \mathrm{~h}$ with biotinylated goat antifluorescein detection antibody, followed by a 20-min incubation with streptavidin-conjugated horseradish peroxidase (diluted 1:200; R\&D Systems, Minneapolis, MN). The color reaction was developed for 2 min using the Substrate Reagent Pack from R\&D Systems, and it was stopped with $2 \mathrm{~N}$ of $\mathrm{H}_{2} \mathrm{SO}_{4}$. The microplate reading was performed at $450 \mathrm{~nm}$ with a correction for microplate uniformity at $540 \mathrm{~nm}$. The dynamic ranges of these assays (the range of concentrations within the linear part of the log-log plot) were $0.01-1.00$ and $0.1-5.0 \mathrm{ng} / \mathrm{mL}$ for rhPRG4-FITC and 70-kDa dextran, respectively. The intra- and interassay coefficients of variability for the rhPRG4-FITC assay were 3.1 and $4.4 \%$, respectively, whereas those for the $70-\mathrm{kDa}$ dextran assay were 2.8 and $3.9 \%$, respectively.

\section{Western blotting}

At 6,24 , and $48 \mathrm{~h}$ post-TBI, rats were anesthetized (i.p. pentobarbital sodium) and were transcardially perfused with $200 \mathrm{~mL}$ of ice-cold $0.9 \% \mathrm{NaCl}$. Cortical samples were quickly collected and proteins were extracted using isotonic lysis buffer $(150 \mathrm{mM}$ of $\mathrm{NaCl}, 50 \mathrm{mM}$ of Tris- $\mathrm{HCl}$ [pH 7.4], $2 \mathrm{mM}$ of ethylenediaminetetraacetic acid, $0.1 \%$ SDS, $0.5 \%$ sodium deoxycholate, and $1 \%$ Triton X-100), containing protease inhibitors ( $1 \mathrm{mM}$ of benzamidine, $100 \mathrm{U} / \mathrm{mL}$ of aprotinin, $20 \mu \mathrm{g} / \mathrm{mL}$ of antipain, $20 \mu \mathrm{g} / \mathrm{mL}$ of leupeptin, $1 \mu \mathrm{g} / \mathrm{mL}$ of pepstatin $\mathrm{A}$, and $1 \mathrm{mM}$ of phenylmethylsulfonyl fluoride) and phosphatase inhibitors $(10 \mathrm{mM}$ of sodium pyrophosphate, $1 \mathrm{mM}$ of sodium orthovanadate, $1 \mathrm{mM}$ of sodium fluoride, and $1 \mathrm{mM}$ of $\beta$-glycerophosphate). Proteins were resolved with SDS/polyacrylamide gel (4-12\%) electrophoresis under reducing conditions and were transferred onto $0.2-\mu \mathrm{m}$ nitrocellulose membranes (ThermoFisherScientific). After blocking with 5\% ECL Advance Blocking Reagent (GE Healthcare, Little Chalfont, UK) for $1 \mathrm{~h}$ at room temperature, membranes were incubated with primary antibodies overnight at $4^{\circ} \mathrm{C}$. Membranes were subsequently incubated with horseradish peroxidase-conjugated antirabbit, -mouse, or -goat antibody for $2 \mathrm{~h}$ at room temperature.

For detection, Lumigen TMA-6 (Lumigen, Southfield, MI) or SuperSignal West Dura extended duration (Pierce, Rockford, IL) chemiluminescence substrate and the Bio Imaging System Chemi Genius2 (Syngene, Frederick, MD) were used. In the analysis of optical density of the bands on immunoblots, levels of CD68, CLDN5, and albumin were normalized to the levels of $\beta$-actin, whereas levels of phosphorylated IKK $\alpha / \beta$ and ERK1 were normalized to the levels of total phosphorylated and non-phosphorylated forms of these proteins. This analysis was performed using ImageJ software (http://rsb.info.nih.gov/ij/).

\section{Real-time reverse-transcriptase polymerase chain reaction}

Similar to the western blot analysis (see above), at predetermined time points ( $6 \mathrm{~h}$ and 1,3 , and 7 days) post-TBI, rats were anesthetized and were transcardially perfused with $200 \mathrm{~mL}$ of ice-cold $0.9 \% \mathrm{NaCl}$. Cortical samples were quickly collected and total RNA was isolated using NucleoSpin RNA II Kit (MachereyNagel, Düren, Germany). First-strand complementary DNAs were synthesized using oligo(dT) $)_{20}$ primer $(50 \mathrm{pmol})$ and $200 \mathrm{U}$ of SuperScript IV reverse transcriptase. The $20-\mu \mathrm{L}$ reverse-transcription reactions also contained $40 \mathrm{U}$ of RNase inhibitor RNaseOut. For each reaction, $1 \mu \mathrm{g}$ of total RNA was used and the reactions were carried out for $30 \mathrm{~min}$ at $50^{\circ} \mathrm{C}$. Polymerase chain reaction (PCR) was performed in Mastercycler EP Realplex2 (Eppendorf, Hamburg, Germany) using TaqMan chemistry.

The following primers and TaqMan probes were used for TLR4: 5'-GCCAGGATGATGCCTCTCT-3' (forward primer), 5'-
AGGGATTTTGCTGAGATTCTG-3' (reverse primer), 5'-CATT GTTCCTTTCCTGCCTGAGACC-3' (probe); CD44: 5'-TCAA GTGGGAATCAAGACAGTG-3' (forward primer), 5' -TTCTCC TACTGTTGACAGCAATG-3' (reverse primer), 5'-CCACAAC TTCTGGTCCTGCGAGG-3' (probe); LGALS3: 5'-AGAACAAC AGAAGAGTCATCGTG-3' (forward primer), 5'-TTGACCGC AACCTTGAAGT-3' (reverse primer), 5'-CAACACGAAGCA GGACAATAACTGGG-3' (probe); and PRG4: 5'-GTGCCCAT CAAAGCCTCTT-3' (forward primer), 5'-GCGTAGTAATCAT AGCCGTCA-3' (reverse primer), 5'-TTCCTCCACAATGAAGT CAAAGTGAGC-3' (probe). Peptidylprolyl isomerase A/cyclophilin A (PPIA) was used for normalization of the data obtained. ${ }^{38}$ The $25-\mu \mathrm{L}$ PCR reaction mixtures contained $0.2 \mathrm{mM}$ of mixed 2'deoxynucleoside 5'-triphosphate, $0.2 \mu \mathrm{M}$ each primer, $0.1-\mu \mathrm{M}$ TaqMan probe, $5 \mathrm{mM}$ of $\mathrm{MgCl}_{2}, 1 \mathrm{U}$ of HotStart Taq DNA polymerase, and $1 / 40$ of the reverse-transcription reaction product. For PPIA, 1/1000 of the reverse transcription reaction product was used. The reaction mixtures were heated to $95^{\circ} \mathrm{C}$ for $15 \mathrm{~min}$ and were then subjected to 45 cycles of denaturation $\left(94^{\circ} \mathrm{C}, 15 \mathrm{sec}\right)$ and annealing/extension $\left(60^{\circ} \mathrm{C}, 60 \mathrm{sec}\right)$.

\section{Evaluation of neuronal death in the injured brain}

Rats received a single i.v. injection of rhPRG4 at $5 \mathrm{mg} / \mathrm{kg}$ or vehicle $(0.9 \% \mathrm{NaCl})$ at $1 \mathrm{~h}$ post-TBI, and 10 weeks later were anesthetized (i.p. pentobarbital sodium) and transcardially perfused with $200 \mathrm{~mL}$ of ice-cold $0.9 \% \mathrm{NaCl}$, followed by $200 \mathrm{~mL}$ of $10 \%$ formalin in PBS. Brains were sectioned at $100 \mu \mathrm{m}$ in the coronal plane using a vibrating microtome. Sections were mounted on glass slides, stained using a standard thionin staining protocol for Nissl substance, and cover-slipped using DPX mounting medium. A Stereo Investigator (MBF Bioscience, Williston, VT) system for stereology, paired with an Olympus BX53 microscope (Olympus, Waltham, MA), was used to trace the somatosensory cortices (barrel fields and upper lip region; bregma -0.8 to $-3.7 \mathrm{~mm})^{42}$ in the ipsi- and contralateral hemispheres across five serial sections for each rat.

Stereo Investigator's optical fractionator workflow was used to perform neuronal cell counts within the traced areas of interest. Neuronal cell counts were performed using a $100 \times$ oil lens with fractionator counting frames set at $50 \times 50 \mu \mathrm{m}$ and grid size of $1200 \times 1200 \mu \mathrm{m}$ reflecting the distribution of counting zones within the traced area of interest. This system was utilized to ensure unbiased, systematic random sampling of neurons within the region of interest. The estimated number of neurons within the region of interest was calculated using the Stereo Investigator software, which accounted for mean section thickness, the traced area of interest, and the number of neuronal counts within each counting frame (site).

\section{Statistical analysis}

For statistical evaluation of data, one- or two-way analysis of variance was used, followed by the Dunnett or Newman-Keuls test for multiple comparisons. Results are presented as mean values \pm SEM. $p \leq 0.05$ was considered statistically significant.

\section{Results}

\section{Post-traumatic upregulation of cortical messenger RNA for putative targets for proteoglycan 4}

Our previous in vitro studies ${ }^{31,33}$ have suggested that TLR2/4 and CD44 are the targets for PRG4 in the injured brain. Using reverse-transcription PCR (RT-PCR), we determined whether TBI has an effect on expression of these receptors in the injured cortex. The expression of both TLR4 and CD44 in sham-injured 
TLR4

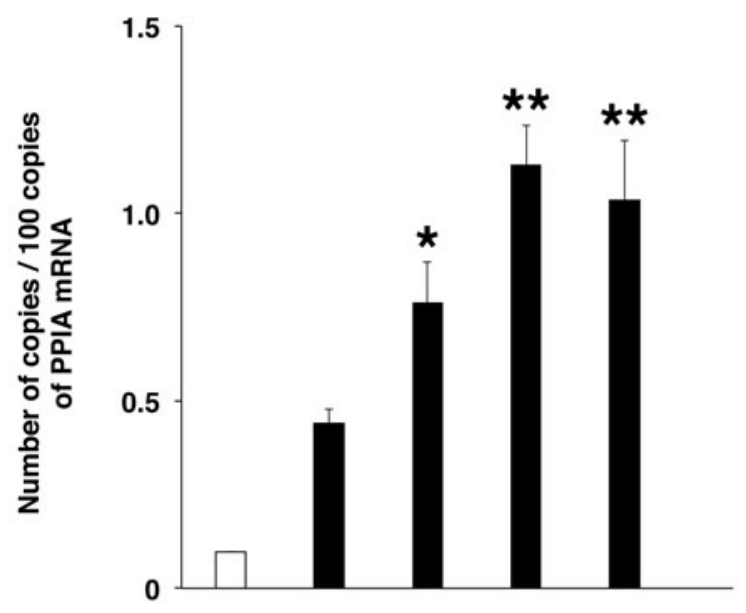

LGALS3

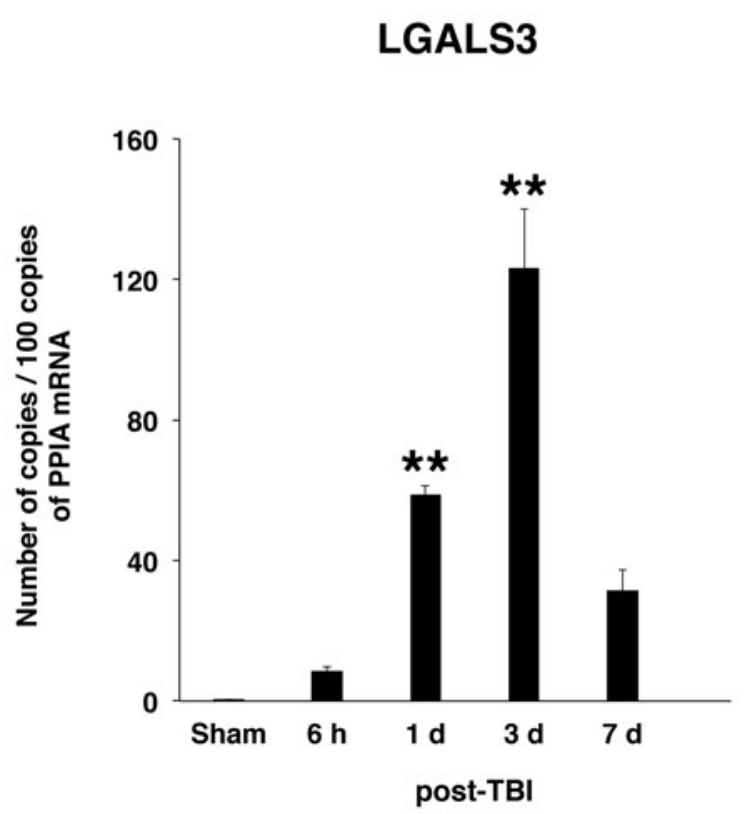

CD44

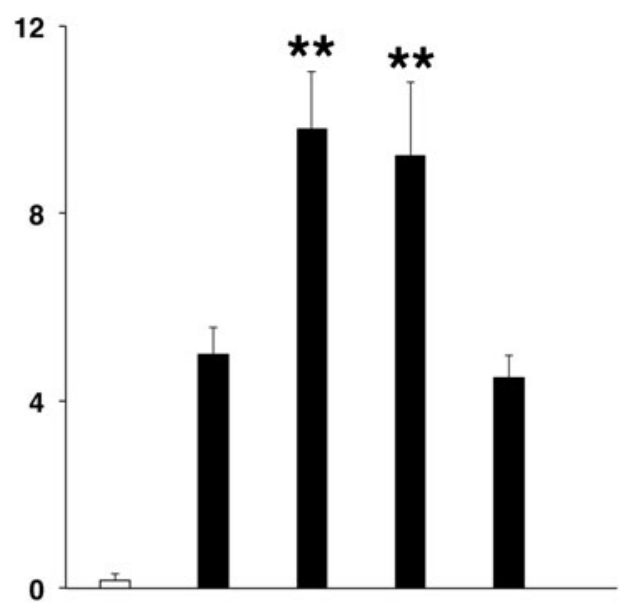

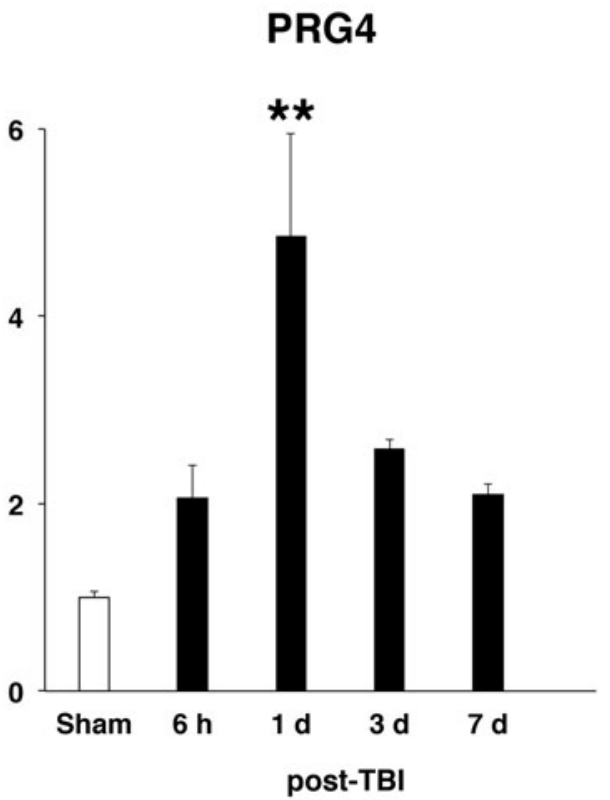

FIG. 1. Post-traumatic changes in cortical mRNA for TLR4, CD44, LGALS3, and PRG4 as assessed by real-time RT-PCR. LGALS3 represents an example of endogenous ligands for TLRs and/or CD44 released/produced after neurotrauma. Peptidylprolyl isomerase A/cyclophilin A (PPIA) was used for normalization of the data obtained. $* p<0.05$; $* *<0.01$ for injured cortex versus sham $(n=4$ per group). CD44, cluster of differentiation 44; LGALS3, galectin 3; mRNA, messenger RNA; PRG4, proteoglycan 4; RT-PCR, reversetranscription polymerase chain reaction; TLRs, Toll-like receptors.

rats was low, but it increased rapidly after TBI, with the TLR4 expression continuing to be highly upregulated for at least 1 week after injury, and the CD44 expression reaching a peak at 1-3 days post-TBI and then decreasing at 7 days after injury (Fig. 1). The cortical message for TLR2 was found to be upregulated after TBI as well (data not shown). We also investigated whether the cortical expression of endogenous ligands for these receptors, such as LGALS3, ${ }^{23}$ would also be upregulated after TBI. The cortical expression of LGALS3 increased rapidly after TBI, peaking at 3 days after injury. Interestingly, we found that PRG4 is expressed in the cerebral cortex and that its message increased $\sim 5$-fold at 1 day post-TBI.

\section{Biological activity of fluorescein isothiocyanate-labeled recombinant human proteoglycan 4}

To determine whether labeling with FITC affected the biological activity of rhPRG4, we used a bioassay based on the human brain endothelial cell line, hCMEC/D3 ${ }^{37}$ These cells express TLR $4,{ }^{43}$ and we examined whether the presence of FITC had an effect on rhPRG4's ability to inhibit the LPS-induced activation of TLR4. Changes in synthesis of IL- 6 were monitored as the assay readout given that the promoter region of the IL6 gene has a putative binding site for nuclear factor kappa B (NF- $\kappa \mathrm{B}),{ }^{44}$ a transcription factor activated by TLR $4 .{ }^{45}$ These experiments demonstrated that FITC-labeled rhPRG4 had full 
biological activity, which was indistinguishable from that observed for unlabeled rhPRG4 (Supplementary Fig. S1B).

\section{Transport of proteoglycan 4 across the blood-brain barrier}

An important question that we initially asked was whether PRG4 can cross the BBB. If so, PRG4 would not only target the BBB and circulating inflammatory cells (see below), but could also reach brain parenchymal cells, such as microglia, which express TLRs and CD44. ${ }^{46,47}$ To this end, the in vitro BBB model was used and the transfer rate of FITC-labeled rhPRG4 across brain endothelial monolayers was measured. The endothelial monolayers expressed TLR2, TLR4, and CD44 (data not shown) and exhibited low permeability to sucrose $\left(\mathrm{Pe}=0.16 \pm 0.03 \mu \mathrm{Lmin}^{-1} \mathrm{~cm}^{-2}\right)$. PRG4 had no effect on the integrity (paracellular permeability) of endothelial
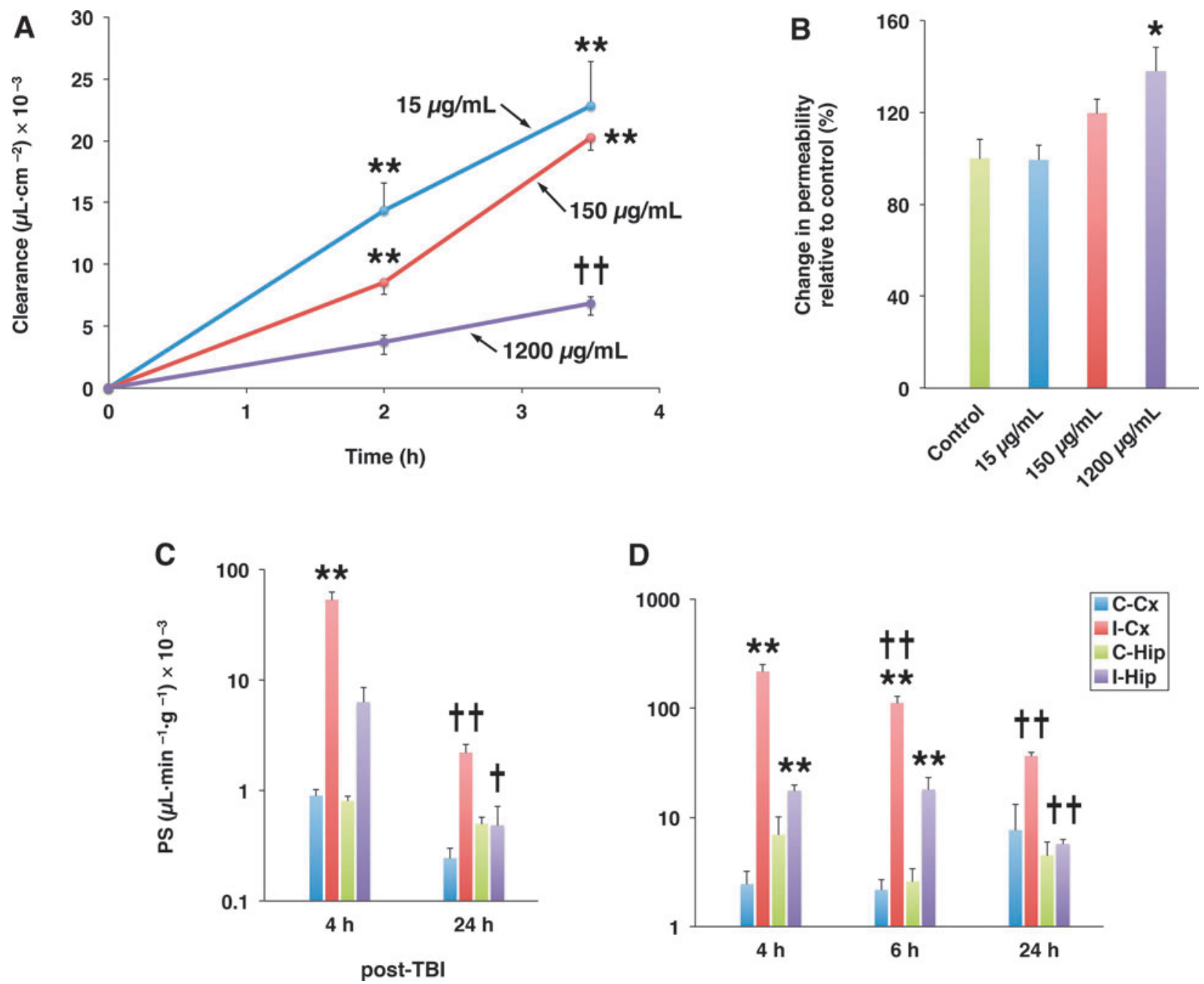

D

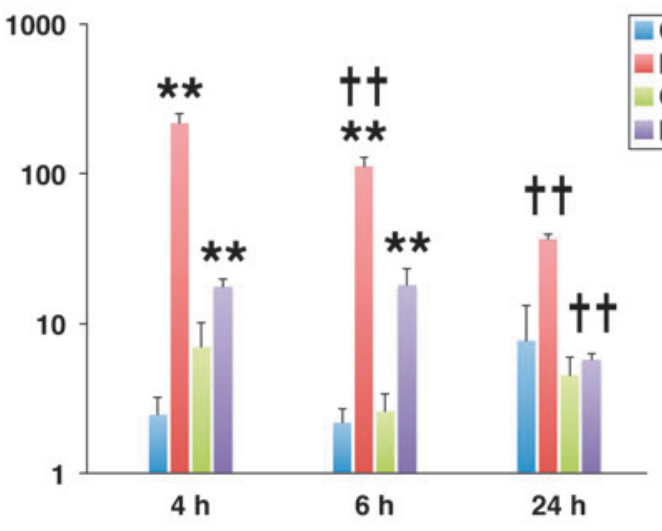

FIG. 2. Transport of PRG4 across the BBB. (A) Transport of PRG4 across brain endothelial monolayers. In these experiments, the in vitro $\mathrm{BBB}$ model based on primary cultures of rat brain endothelial cells was used. Transfer of PRG4 across endothelial monolayers and its putative saturability were evaluated in the luminal-to-abluminal direction. FITC-labeled rhPRG4 was added to the culture media to achieve the concentration of 15 or $150 \mu \mathrm{g} / \mathrm{mL}$, or was mixed with unlabeled rhPRG4 in the 1:8 proportion, so that the final concentration of total rhPRG4 amounted to $1200 \mu \mathrm{g} / \mathrm{mL}$. Note that at concentrations of 15 and $150 \mu \mathrm{g} / \mathrm{mL}$, PRG4 was transported across monolayers at similar rates. However, the clearance rate of PRG4 fell sharply when its concentration was increased to $1200 \mu \mathrm{g} / \mathrm{mL}$, indicating that PRG4 crosses the BBB through a saturable transport system. $* * p<0.01$ compared to the preceding time point; ${ }^{\dagger p} p<0.01$ compared to 15 or $150 \mu \mathrm{g} / \mathrm{mL}$ ( $n=3-4$ per group). (B) Permeability of endothelial monolayers to ${ }^{14} \mathrm{C}$-sucrose. Under control conditions, monolayers exhibited low permeability to sucrose $\left(\mathrm{Pe}=0.16 \pm 0.03 \mu \mathrm{Lmin}^{-1} \mathrm{~cm}^{-2}\right)$. Note that after a 2-h incubation, PRG4 had no effect on the integrity (paracellular permeability) of endothelial monolayers, except when the highest, supratherapeutic concentration $(1200 \mu \mathrm{g} / \mathrm{mL}) \mathrm{of} \mathrm{rhPRG} 4$ was used, which caused a small increase in permeability to sucrose amounting to $138 \pm 10 \%$ of control value. ${ }^{*} p<0.05$ compared to control ( $n=3$ per group). (C) BBB permeability to PRG4 in injured rats. FITC-labeled rhPRG4 was injected i.v. at $3 \mathrm{mg} / \mathrm{kg}$ at $4 \mathrm{and} 24 \mathrm{~h}$ post-TBI and was allowed to circulate for $40 \mathrm{~min}$. Note that PRG4 delivery to the brain was facilitated by a post-traumatic increase in permeability of the BBB (see D). Later, after injury ( $24 \mathrm{~h}$ post-TBI), the efficiency of brain delivery of PRG4 was reduced, which correlated with a decrease in BBB permeability. (D) Post-traumatic changes in BBB permeability to fluorescein-conjugated dextran of 70-kDa. Dextran (70$\mathrm{kDa}$ ) was injected i.v. at $2 \mathrm{mg} / \mathrm{kg}$ and was allowed to circulate for $30 \mathrm{~min}$. $* * p<0.01$ for the ipsi- versus contralateral cortex/hippocampus; ${ }^{\dagger} p<0.05 ;{ }^{\dagger \dagger} p<0.01$ compared to the preceding time point post-TBI $(n=3$ per group). I-Cx and C-Cx are the ipsi- and contralateral cortices, respectively. I-Hip and C-Hip are the ipsi- and contralateral hippocampi, respectively. BBB, blood-brain barrier; FITC, fluorescein isothiocyanate; i.v., intravenously; PRG4, proteoglycan 4; rhPRG4, recombinant human PRG4; TBI, traumatic brain injury. 
monolayers, except when the highest, supratherapeutic rhPRG4 concentration $(1200 \mu \mathrm{g} / \mathrm{mL})$ was used, which caused a small increase in the permeability to sucrose amounting to $138 \pm 10 \%$ of control value (Fig. 2B). At concentrations of 15 and $150 \mu \mathrm{g} / \mathrm{mL}$ in the upper (luminal) compartment, PRG4 was transported across the monolayers at similar rates (Fig. 2A). However, the clearance rate of PRG4 fell sharply when its concentration was increased to $1200 \mu \mathrm{g} / \mathrm{mL}$, indicating that PRG4 crosses the BBB through a saturable transport system.

In rats sustaining TBI, PRG4 delivery to the brain (Fig. 2C) was facilitated by post-traumatic increase in permeability of the
BBB (Fig. 2D). Forty minutes after its early post-injury (4 h postTBI) administration, PRG4 found in the traumatized cortex was still in its intact form, although two distinct PRG4 degradation products of $\sim 60$ and $\sim 12 \mathrm{kDa}$ were also observed (Fig. 3A). The $\sim 12$-kDa degradation product may represent the mature peptide with a theoretical molecular weight of $11.1 \mathrm{kDa}{ }^{48}$ Later, after injury ( $24 \mathrm{~h}$ post-TBI), brain delivery of PRG4 and the proportion of PRG4 in its intact form relative to its degradation products found in the injured cortex were decreased. In plasma, a limited degradation of PRG4 was observed during its 40-min circulation period (Fig. 3B).
A

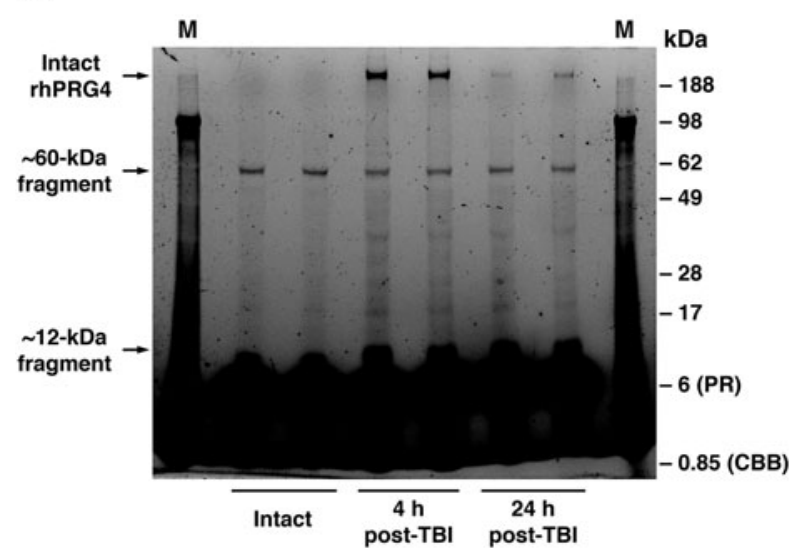

C

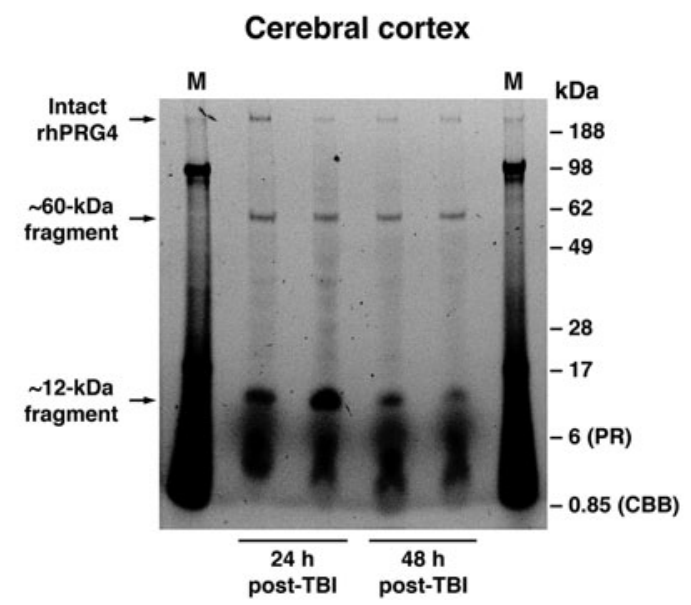

B

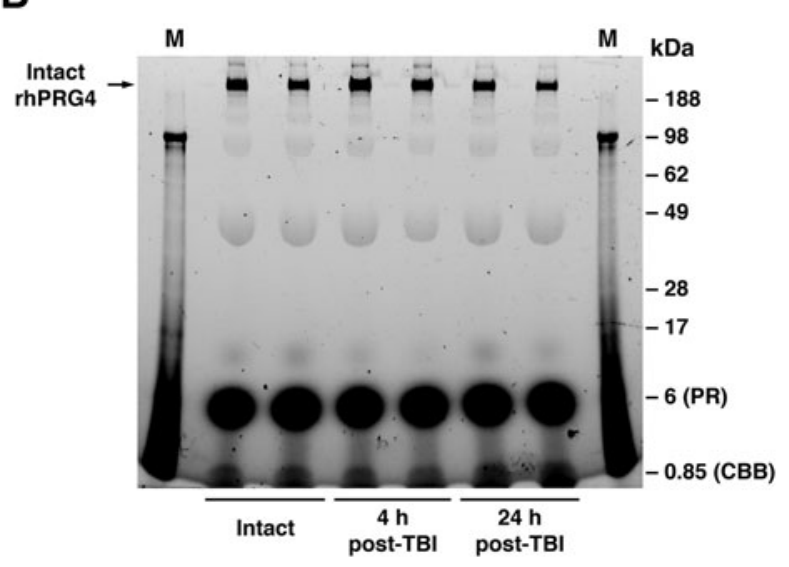

D

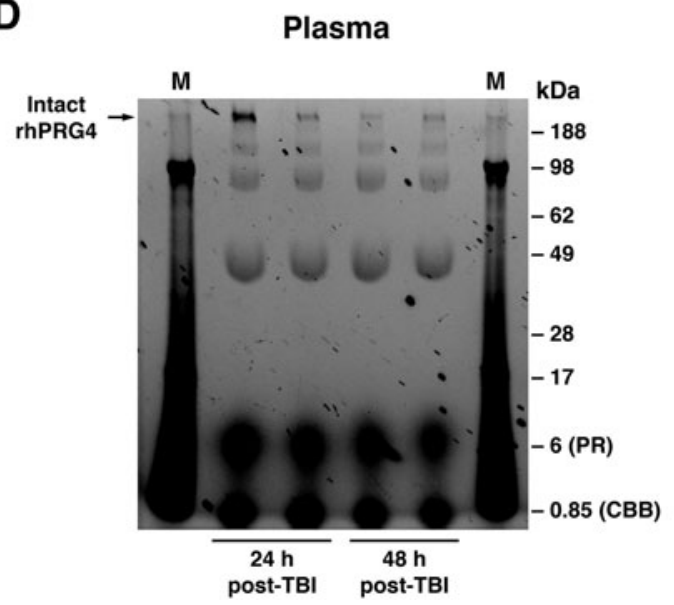

FIG. 3. Degradation of PRG4 in traumatized cortical tissue and plasma. rhPRG4-FITC was injected i.v. at $3 \mathrm{mg} / \mathrm{kg}$ to either intact rats or to rats sustaining TBI at 4 or $24 \mathrm{~h}$ after injury, and was allowed to circulate for $40 \mathrm{~min}$. The samples of the ipsilateral cortex (A) and plasma (B) were analyzed using SDS/polyacrylamide gel electrophoresis under non-reducing conditions. Note the presence of two distinct PRG4 degradation products of $\sim 60$ and $\sim 12 \mathrm{kDa}$ in the cortex of both intact and injured animals. After its early post-injury ( $4 \mathrm{~h}$ post-TBI) administration, the significant amount of PRG4 found in the traumatized cortex was still in its intact form; however, when rhPRG4 was injected later after injury $(24 \mathrm{~h}$ post-TBI), the proportion of its intact form relative to its degradation products was decreased. The high-intensity signals observed in the lower parts of the gels result from autofluorescence of phenol red (PR; migrating at $6 \mathrm{kDa}$ ) and Coomassie Brilliant Blue G-250 (CCB; $850 \mathrm{Da}$ ), which were the constituents of the sample buffer used. Compared to the cerebral cortex, in plasma, there was very limited degradation of PRG4 observed during its 40-min circulation period. In a separate series of experiments, rhPRG4-FITC was administered at $4 \mathrm{~h}$ after injury, and rats were euthanized at 24 or $48 \mathrm{~h}$ post-TBI. Samples of the ipsilateral cortex (C) and plasma (D) were analyzed as described above. Note the prolonged presence of 60- and 12-kDa PRG4 degradation products in the injured cortex, which may be responsible for protracted biological activity of rhPRG4 observed after its single injection. In contrast, PRG4 found in plasma at 24 and $48 \mathrm{~h}$ post-TBI was highly degraded with multiple degradation fragments whose molecular weights differed from those of PRG4 degradation products observed in the injured cortex. M indicates protein standards. On each gel, the data from 2 individual animals for a given time point/experimental conditions are shown. FITC, fluorescein isothiocyanate; i.v., intravenously; PRG4, proteoglycan 4; rhPRG4, recombinant human PRG4; SDS, sodium dodecyl sulfate; TBI, traumatic brain injury. 
A

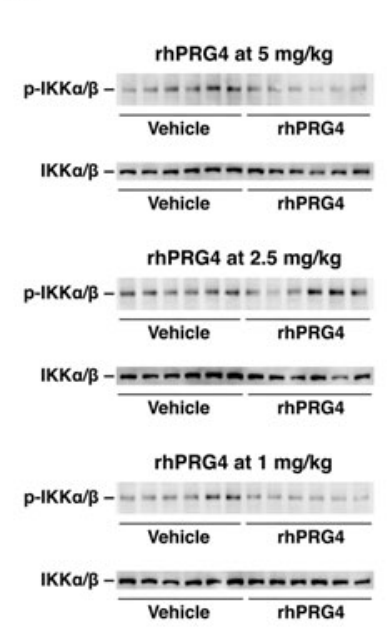

$6 \mathrm{~h}$ post-TBI

p-IKKa/ $/ / \mathrm{IKKa} / \beta$
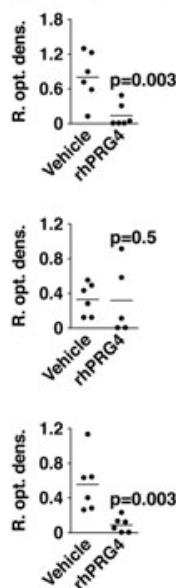

$24 \mathrm{~h}$ post-TBI
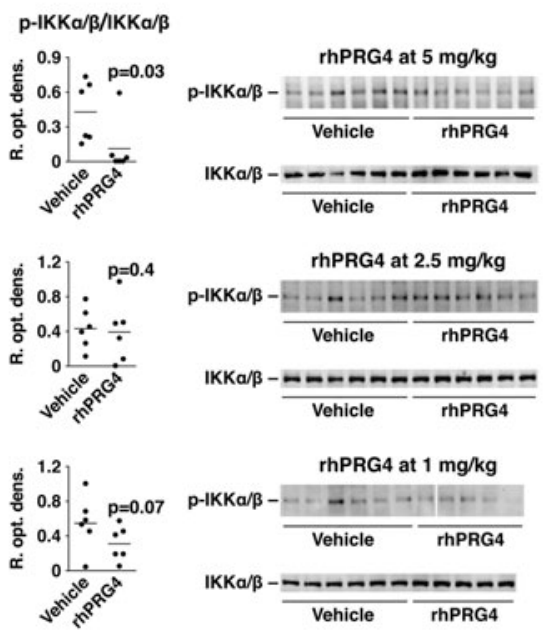

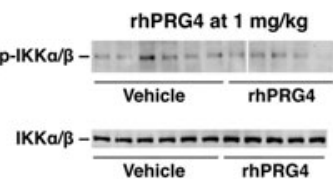

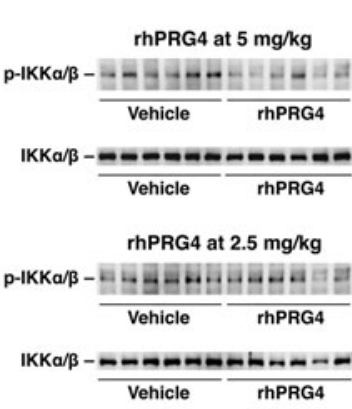

rhPRG4 at $1 \mathrm{mg} / \mathrm{kg}$

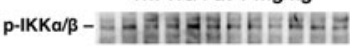

IKKa/ $/$ -
p-IKKa/ $/ / \mathrm{IKKa} / \beta$
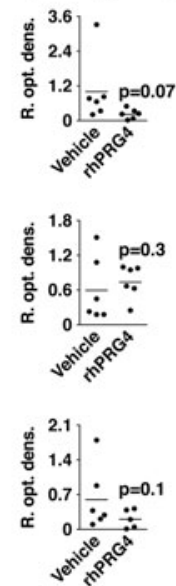

B

$6 \mathrm{~h}$ post-TBI
p-ERK1/ERK1

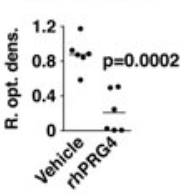

rhPRG4 at $2.5 \mathrm{mg} / \mathrm{kg}$

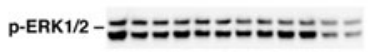

ERK1/2-ニニニニニニニニニニニニ Vehicle

rhPRG4 at $1 \mathrm{mg} / \mathrm{kg}$

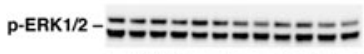

ERK1/2-ニニニニニニニニニニニニ Vehicle rhPRG4

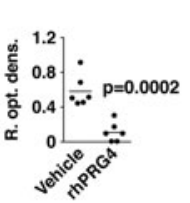

$24 \mathrm{~h}$ post-TBI

$48 \mathrm{~h}$ post-TBI
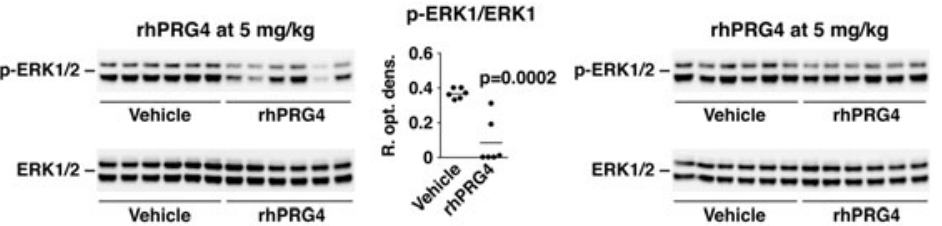

p-ERK1/ERK1

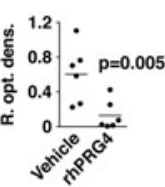

rhPRG4 at $2.5 \mathrm{mg} / \mathrm{kg}$
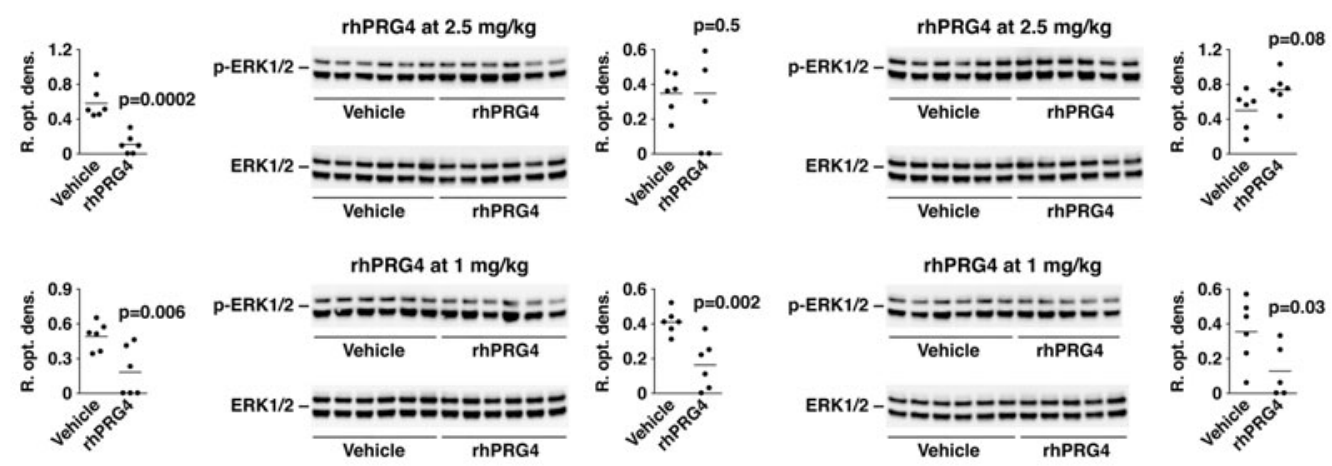

C

p-IKKa/ $/ / \mathrm{IKKa} / \beta$

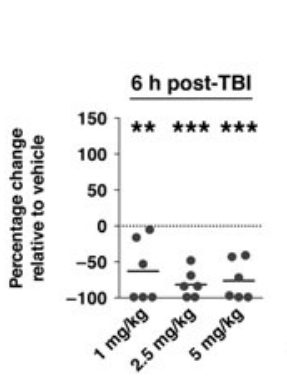

p-ERK1/ERK1
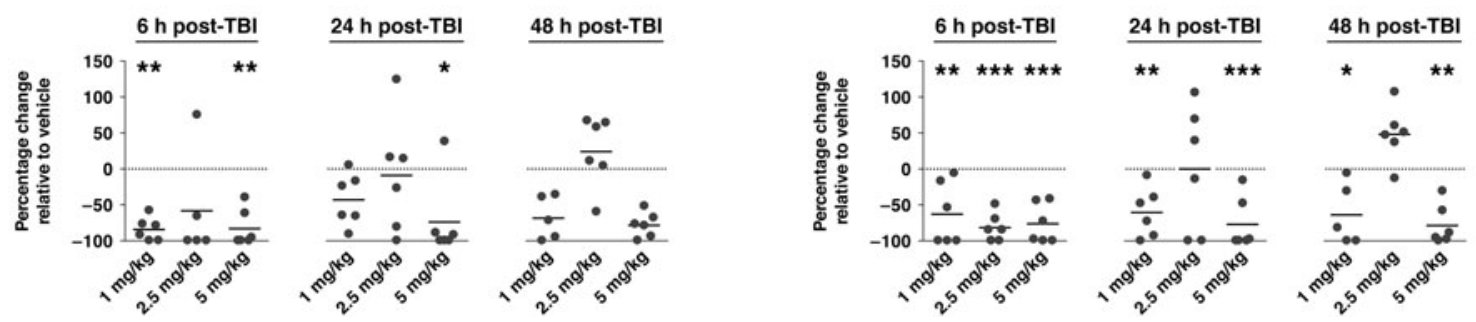

FIG. 4. Inhibitory effect of PRG4 on post-traumatic activation of NF- $\kappa \mathrm{B}$ and ERK $1 / 2$ signaling cascades. rhPRG4 was injected i.v. at $1 \mathrm{~h}$ post-TBI at doses ranging from 1 to $5 \mathrm{mg} / \mathrm{kg}$. $\mathrm{NaCl}$ solution $(0.9 \%)$ was used as a vehicle. Extent of activation of the $\mathrm{NF}-\kappa \mathrm{B}$ signaling pathway in the injured cortex (A) was determined by assessing the level of phosphorylation (p) of IKK $\alpha / \beta$ on western blots. Extent of post-traumatic activation of ERK1/2 (B) was assessed based on the level of its phosphorylation. (C) Summary graphs illustrating the inhibitory effect of PRG4 on post-traumatic activation of IKK $\alpha / \beta$ and ERK1/2. PRG4 appears to inhibit activity of ERK1/2 with a higher efficacy than that of the NF- $\kappa$ B signaling cascade. Note that the lowest and highest rhPRG4 doses used (1 and $5 \mathrm{mg} / \mathrm{kg}$ ) were the most effective in inhibiting post-traumatic activation of ERK1/2, especially at 24 and $48 \mathrm{~h}$ post-TBI. $* p<0.05$; $* * p<0.01$ for rhPRG4 versus vehicle ( $n=5-6$ per group). ERK1/2, extracellular signal-regulated kinases $1 / 2$; IKK $\alpha / \beta$, I $\kappa \mathrm{B}$ kinase $\alpha / \beta$; i.v., intravenously; NF- $\kappa$ B, nuclear factor kappa B; p-ERK1/2, phosphorylated ERK1/2; p-IKK $\alpha / \beta$, phosphorylated IKK $\alpha / \beta$; PRG4, proteoglycan 4; rhPRG4, recombinant human PRG4; SDS, sodium dodecyl sulfate; TBI, traumatic brain injury. 
The inhibitory effect of proteoglycan 4 on post-traumatic activation of nuclear factor kappa $B$ and extracellular signal-regulated kinases 1/2, and the influx of monocytes

PRG4 binds to TLR2/4 and CD44 and interferes with their signaling. ${ }^{31,33}$ Given that the NF- $\kappa \mathrm{B}$ signaling cascade is one of the major signal transduction pathways associated with TLR $2 / 4^{45}$ and ERK1/2 are stimulated by both TLR2/4 and CD44, ${ }^{45,49}$ we investigated whether PRG4 inhibits post-traumatic activation of these signaling pathways. To this end, rhPRG4 was injected i.v. at $1 \mathrm{~h}$ post-TBI at doses ranging from 1 to $5 \mathrm{mg} / \mathrm{kg}$, and we analyzed the cortical tissue samples on western blots at 6,24 , and $48 \mathrm{~h}$ after injury. The extent of activation of the NF- $\kappa \mathrm{B}$ signaling pathway was determined by assessing the level of phosphorylation of IKK $\alpha / \beta$. Compared to vehicle-treated rats, PRG4 significantly inhibited post-traumatic activation of NF- $\kappa \mathrm{B}$ and ERK1/2 (Fig. 4), suggesting that it may interfere with TLR2/4 and CD44 signaling in the injured brain. PRG4 appeared to inhibit activity of the ERK1/2 pathway with a higher efficacy than that of the NF$\kappa \mathrm{B}$ signaling cascade. Interestingly, the lowest and highest rhPRG4 doses used ( 1 and $5 \mathrm{mg} / \mathrm{kg}$ ) were most effective in inhibiting the post-traumatic activation of ERK1/2, especially at 24 and $48 \mathrm{~h}$ post-TBI.

Consistent with these results, and the role of TLR2/4 and CD44 in leukocyte trafficking, PRG4 was found to curtail the posttraumatic influx of monocytes (Fig. 5). This was evaluated by assessing the cortical levels of CD68, a monocyte marker. It is important to note that, similar to its inhibitory effect on posttraumatic activation of ERK1/2, a single post-injury injection of rhPRG4 was therapeutically effective (albeit with diminishing efficacy) in limiting the monocyte influx for at least $48 \mathrm{~h}$ after TBI.

\section{The protective effect of proteoglycan 4 on the blood-brain barrier}

Neurotrauma is associated with a rapid increase in BBB permeability. ${ }^{3}$ We examined the effect of PRG4 on BBB permeability by assessing the amount of albumin accumulating in the injured cortex. Similar to its inhibitory effect on post-traumatic activation of ERK1/2 and the influx of monocytes (see above), a single injection of rhPRG4 at $1 \mathrm{~h}$ post-injury reduced the leakiness of the BBB for at least $48 \mathrm{~h}$ after TBI (Fig. 6A,B). Delayed ( $4 \mathrm{~h}$ post-TBI) administration of rhPRG4 was also found to be highly efficacious in restoring normal BBB function after TBI (Fig. 6C). To elucidate the possible mechanisms underlying this PRG4 action, we investigated whether PRG4 has an effect on post-traumatic expression of TJ proteins. In this analysis, we focused on CLDN5 given that this TJ protein plays a critical role in controlling the permeability of the BBB. ${ }^{50}$ Using western blots, we previously showed that expression of CLDN5 in the injured cortex is reduced during the first $24 \mathrm{~h}$ postTBI, but it recovers at $48 \mathrm{~h}$ after injury (Supplementary Fig. S2B). PRG4 was found to reverse a decrease in cortical expression of CLDN5 at 6 and $24 \mathrm{~h}$ after injury, but not at $48 \mathrm{~h}$ post-TBI (Fig. 6D), which was consistent with our previous findings.

\section{The neuroprotective effect of proteoglycan 4 in traumatic brain injury}

To evaluate the neuroprotective effect of PRG4, we estimated the number of neurons in the primary somatosensory cortices in the ipsi- versus contralateral hemisphere. In this series of experiments, rats received a single i.v. injection of rhPRG4 at $5 \mathrm{mg} / \mathrm{kg}$ at $1 \mathrm{~h}$ postTBI and the neuroprotective effect of PRG4 was assessed 10 weeks after injury. As expected, the analysis of the ipsi-/contralateral ratio of a number of neurons in the somatosensory cortex showed a
A

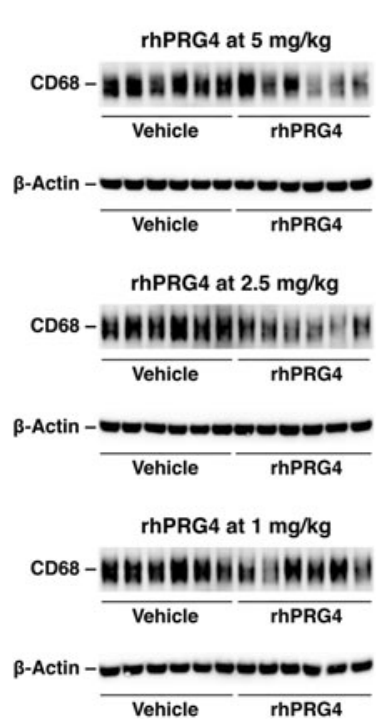

$24 \mathrm{~h}$ post-TBI
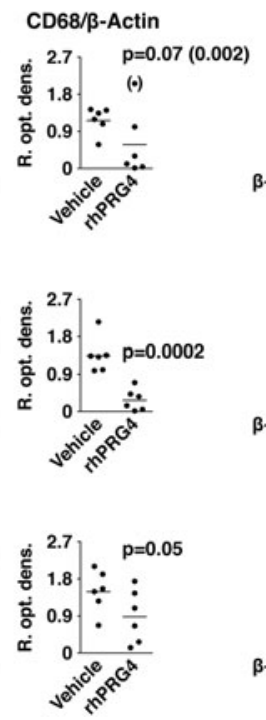

$48 \mathrm{~h}$ post-TBI

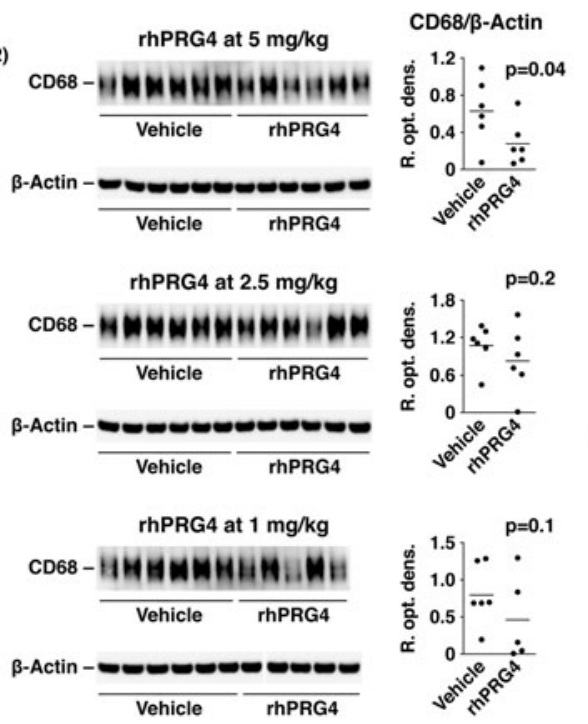

B CD68/ß-Actin

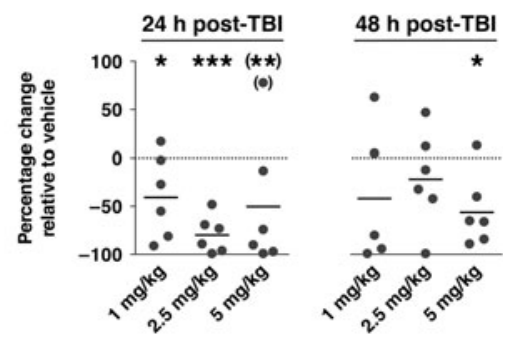

FIG. 5. Inhibitory effect of PRG4 on post-traumatic invasion of monocytes. rhPRG4 was injected i.v. at $1 \mathrm{~h}$ post-TBI at $1-5 \mathrm{mg} / \mathrm{kg}$, and cortical levels of CD68, a monocyte marker, were assessed using western blots (A). $\mathrm{NaCl}$ solution $(0.9 \%)$ was used as a vehicle. (B) Summary graph illustrating the inhibitory effect of PRG4 on post-traumatic invasion of monocytes. Note that, similar to its inhibitory effect on activation of ERK1/2, a single post-injury injection of rhPRG4 was therapeutically effective (albeit with diminishing efficacy) in limiting the monocyte influx for at least $48 \mathrm{~h}$ after TBI. $* p<0.05 ; * *<0.01$ for rhPRG4 versus vehicle ( $n=5-6$ per group). CD68, cluster of differentiation 68; ERK1/2, extracellular signal-regulated kinases 1/2; i.v., intravenously; PRG4, proteoglycan 4; rhPRG4, recombinant human PRG4; TBI, traumatic brain injury. 


\section{A $6 \mathrm{~h}$ post-TBI}

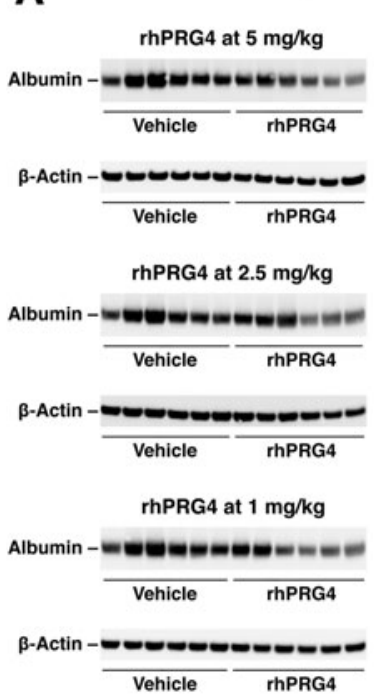

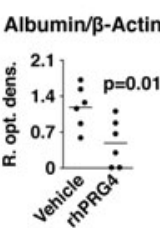
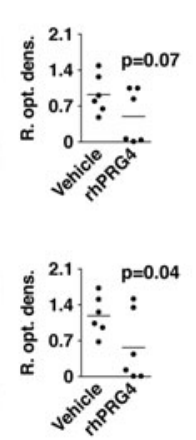

24 h post-TBI
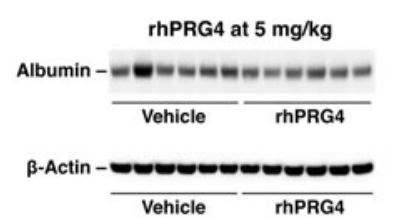

rhPRG4 at $2.5 \mathrm{mg} / \mathrm{kg}$
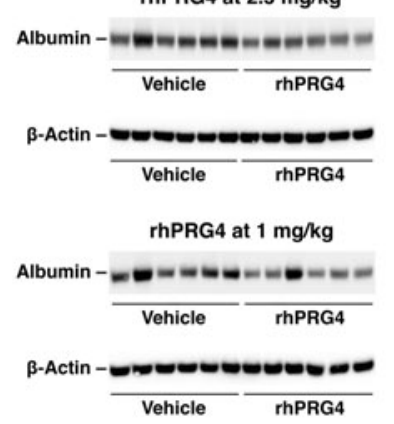
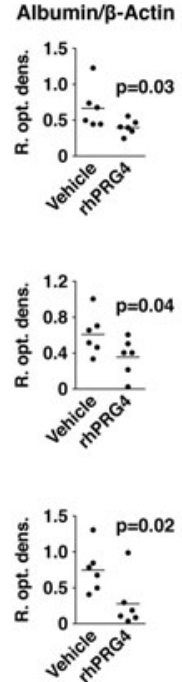

$48 \mathrm{~h}$ post-TBI

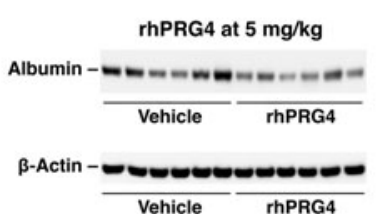

Albumin/ $\beta$-Actin
B

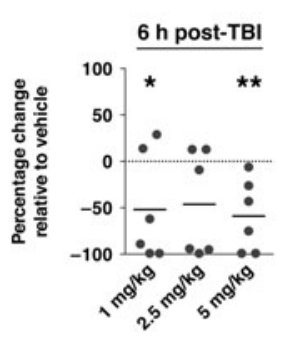

Albumin/ $\beta$-Actin

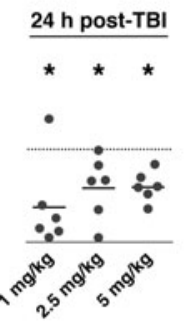

$48 \mathrm{~h}$ post-TBI
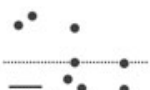

$\div \stackrel{\bullet}{\bullet}$

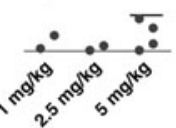

rhPRG4 at $1-5 \mathrm{mg} / \mathrm{kg}$ i.v. (1 h post-TBI)

C

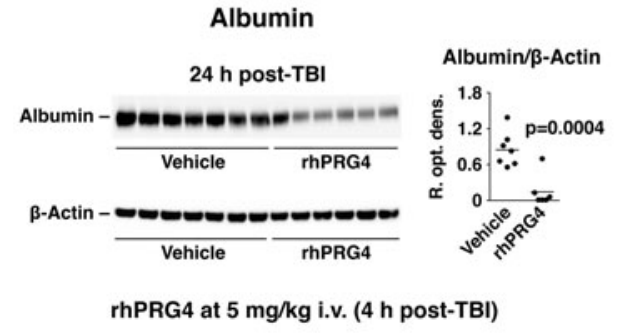

D

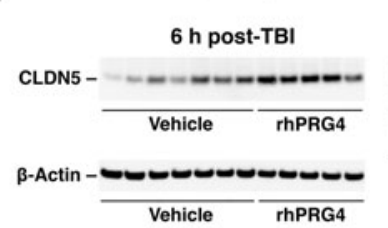

$24 \mathrm{~h}$ post-TBI
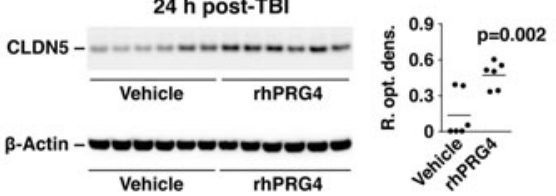

CLDN5/ $\beta$-Actin
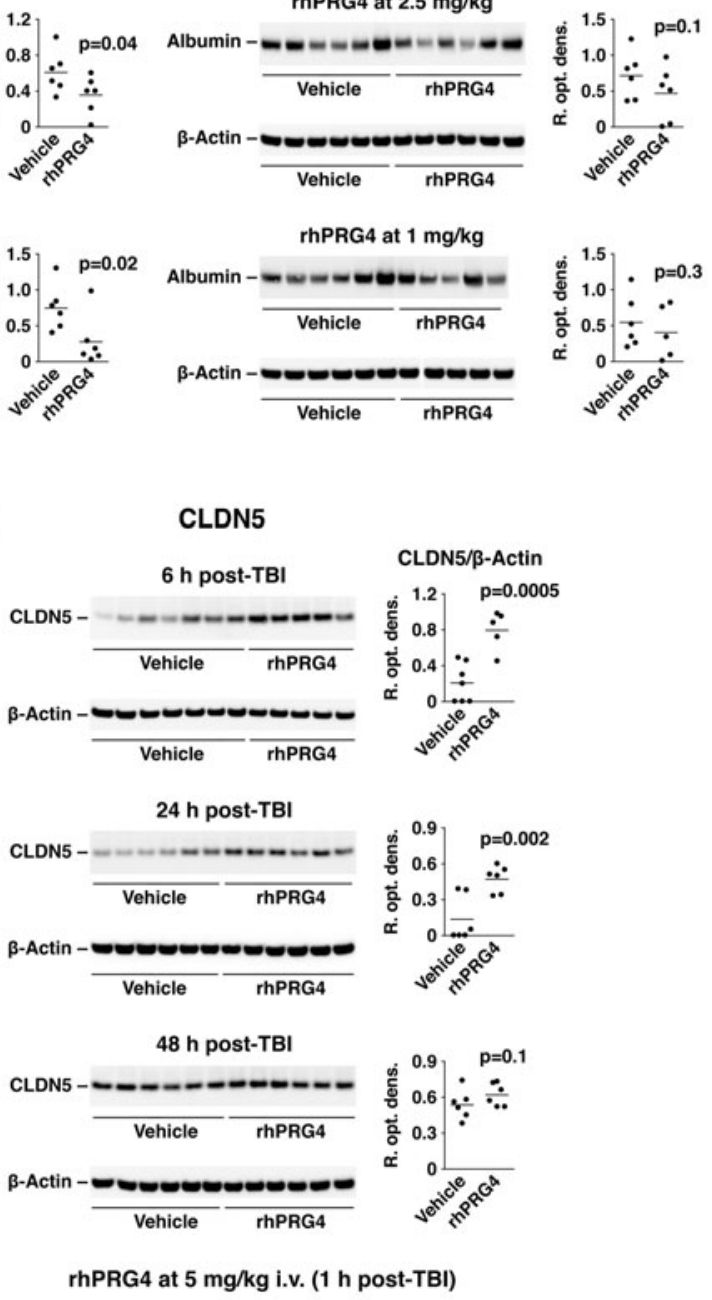

FIG. 6. Protective effect of PRG4 on the BBB. rhPRG4 was injected i.v. at $1 \mathrm{~h}$ post-TBI at $1-5 \mathrm{mg} / \mathrm{kg}$, and cortical tissue samples were analyzed on western blots at 6,24 , and $48 \mathrm{~h}$ after injury. $\mathrm{NaCl}$ solution $(0.9 \%)$ was used as a vehicle. (A) Effect of PRG4 on BBB permeability was evaluated by assessing the amount of albumin accumulating in the injured cortex. (B) Summary graph illustrating the inhibitory effect of PRG4 on post-traumatic increase in BBB permeability. Note that a single injection of rhPRG4 at $1 \mathrm{~h}$ post-injury effectively reduced the leakiness of the BBB for at least $48 \mathrm{~h}$ after TBI. $* p<0.05 ; * *<<0.01$ for rhPRG4 versus vehicle $(n=5-6$ per group). (C) Delayed ( $4 \mathrm{~h}$ post-TBI) administration of rhPRG4 at $5 \mathrm{mg} / \mathrm{kg}$ ( $n=6-7$ per group) was also highly efficacious in restoring normal BBB function after TBI. (D) Effect of PRG4 on post-traumatic expression of TJ protein CLDN5 in the injured cortex $(n=6$ per group). Note that PRG4 reversed a decrease in cortical expression of CLDN5 at 6 and $24 \mathrm{~h}$ post-TBI. At $48 \mathrm{~h}$ after injury, a spontaneous recovery in CLDN5 expression normally occurs (see Supplementary Fig. S2B), so no effect of PRG4 on cortical CLDN5 expression was observed at that time point post-TBI. BBB, blood-brain barrier; CLDN5, claudin 5; i.v., intravenously; PRG4, proteoglycan 4; rhPRG4, recombinant human PRG4; TBI, traumatic brain injury; TJ, tight junction.

widespread neuronal death in injured, vehicle-treated rats versus sham-injured animals ( $p=0.05$; Fig. 7C). When compared to vehicle, PRG4 did not significantly increase the ipsi-/contralateral ratio of a number of somatosensory neurons $(p=0.4)$; however, this ratio in TBI rats treated with rhPRG4 did not differ from that found in sham-injured animals $(p=0.4)$, suggesting the possible neuroprotective effect of PRG4.

\section{Discussion}

An important finding of this study is a prolonged upregulation of message for TLR2/4 and CD44 after injury. Here, the observation period was limited to 1 week post-TBI; however, based on previous studies, it is likely that expression of TLR2/4 and CD44 in the injured brain could be increased for a longer period of time. Indeed, 
A

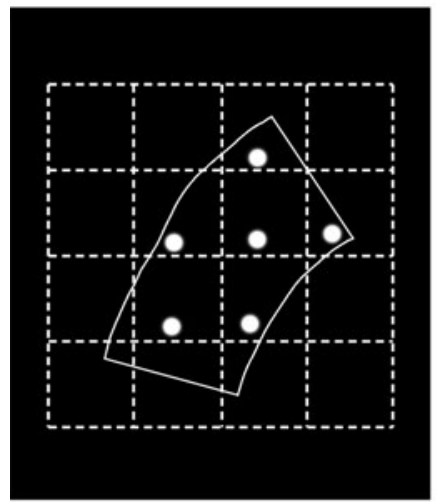

B

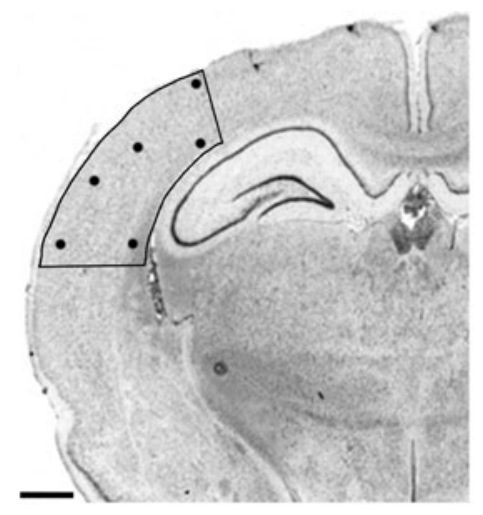

C

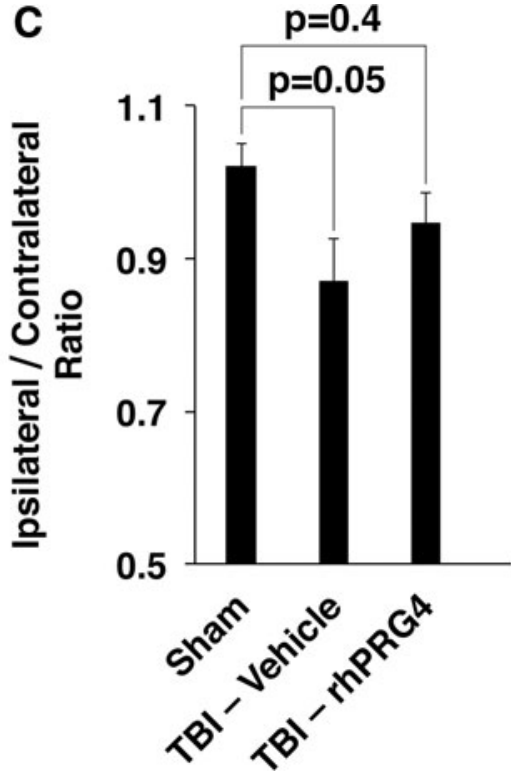

FIG. 7. Neuroprotective effect of PRG4 in TBI. Rats received a single i.v. injection of rhPRG4 at $5 \mathrm{mg} / \mathrm{kg}$ or vehicle $(0.9 \% \mathrm{NaCl})$ at $1 \mathrm{~h}$ post-TBI, and the neuroprotective effect of PRG4 was assessed 10 weeks after injury ( $n=10-12$ per group). A Stereo Investigator system for stereology was used to trace somatosensory cortices in the ipsi- and contralateral hemispheres. (A) Prototypical sample of a single serial tracing from the somatosensory cortex, including the counting sites. (B) Coronal brain section with the tracing and counting sites overlay. Scale bar $=1 \mathrm{~mm}$. (C) Ipsi-/contralateral ratio of a number of neurons in the somatosensory cortex. As expected, this analysis showed a widespread neuronal death in injured, vehicle-treated rats versus sham-injured animals $(p=0.05)$. When compared to vehicle, PRG4 did not significantly increase the ipsi-/contralateral ratio of a number of somatosensory neurons $(p=0.4)$; however, this ratio in TBI rats treated with rhPRG4 did not differ from that found in sham-injured animals $(p=0.4)$, suggesting the possible neuroprotective effect of PRG4. i.v., intravenously; PRG4, proteoglycan 4; rhPRG4, recombinant human PRG4; TBI, traumatic brain injury.

persistent, lasting for months to years, post-traumatic activation of microglia, the cells that highly express TLR2/4 and CD44, has been reported. ${ }^{16-18}$ Given that the post-traumatic increase in brain levels of putative ligands for TLR2/4 and CD44 also appears to be a longlasting phenomenon (see Fig. 1 and Al'Qteishat et al. ${ }^{25}$ ), it is reasonable to hypothesize that the therapeutic targeting of these receptors for an extended period of time post-injury would be advantageous over acute intervention in TBI.

Using the in vitro model of the BBB, we showed that PRG4 can enter the brain through a high-capacity, saturable transport system. Our data indicate that this transport mechanism could easily cope with both physiological $(\sim 2 \mu \mathrm{g} / \mathrm{mL})^{51}$ and potentially therapeutic concentrations of PRG4 in plasma (in rats, plasma levels of rhPRG4 decayed from $\sim 200 \mu \mathrm{g} / \mathrm{mL}$ down to $\sim 20 \mu \mathrm{g} / \mathrm{mL}$ within 40 min after its i.v. injection at $3 \mathrm{mg} / \mathrm{kg}$ ). The nature of PRG4 transport across the $\mathrm{BBB}$ is currently unknown, but, given the size of this protein, it is possible that this transport involves the TLR4- and/or CD44mediated transcytosis of PRG4. Consistent with this idea, the internalization of rhPRG4 associated with TLR4 or CD44 was observed in peritoneal $\mathrm{Prg}^{-1-}$ murine macrophages. ${ }^{28}$ Further, TLR4 and CD44 are expressed on brain endothelium, ${ }^{43,52,53}$ and there is convincing evidence that at least TLR4 is located on its luminal side. ${ }^{52,54}$

In rats sustaining TBI, the PRG4 delivery to the brain, especially early after injury ( $4 \mathrm{~h}$ post-TBI), was facilitated by post-traumatic increase in permeability of the BBB (see Fig. 2D). Later, after injury ( $24 \mathrm{~h}$ post-TBI), the amount of PRG4 delivered to the brain decreased, which correlated with a decrease in BBB permeability. It should be noted that PRG4 was partially proteolytically degraded in the injured cortex, producing two major degradation products of 60 and $12 \mathrm{kDa}$ (see Fig. 3A). This, together with the fact that the
ELISA used to measure the levels of rhPRG4-FITC, could not differentiate between an intact PRG4 and its degradation products had an effect on precision of our PS estimates. Whereas the actual PS values for PRG4 would be difficult, if at all possible, to assess in injured animals, our observations clearly indicate that PRG4 delivery to the brain (especially shortly after injury) is facilitated by post-traumatic increase in BBB permeability. However, it is important to note that, thanks to the presence of a high-capacity transport system for PRG4 at the BBB, this protein may also reach the parenchymal targets in the areas of the brain where the BBB is less leaky, but neurons remain vulnerable to secondary injury.

PRG4 potently inhibits post-traumatic activation of NF- $\kappa \mathrm{B}$ and ERK1/2 signaling pathways, which is in line with our previous observations that PRG4 interferes with both TLR2/4 and CD44 signaling. ${ }^{31-34}$ PRG4 appeared to have a stronger inhibitory effect on activity of ERK1/2 than on that of the NF- $\kappa$ B signaling pathway, and this effect lasted for at least $48 \mathrm{~h}$ after a single rhPRG4 injection at $1 \mathrm{~h}$ post-TBI. This protracted inhibitory activity of PRG4 could be associated with a prolonged presence in the injured brain of its 60- and/or 12-kDa degradation products (Fig. 3C), which may be biologically active, rather than with its slow elimination from the circulation. Indeed, PRG4 found in plasma at 24 and $48 \mathrm{~h}$ post-TBI was highly degraded with multiple degradation fragments whose molecular weights differed from those of PRG4 degradation products observed in the injured cortex (Fig. 3D). Plasma concentrations of PRG4 measured by ELISA were as low as $\sim 100 \mathrm{ng} / \mathrm{mL}$ ( $\sim 1$ order of magnitude lower than the reported normal plasma concentration of PRG4), ${ }^{51}$ and this value is an overestimation of the actual levels of intact PRG4 given that the ELISA used could not distinguish an intact PRG4 from its degradation products. 
rhPRG4 was also found to limit the post-traumatic influx of monocytes for at least $48 \mathrm{~h}$ post-TBI after its single injection. The magnitude of monocyte invasion was evaluated by assessing the cortical levels of CD68. Whereas this monocyte marker has been suggested to be also expressed by activated microglia, we have previously found that, within the first $24-48 \mathrm{~h}$ post-TBI, the majority of CD68-positive cells found in the injured brain represent invading monocytes. ${ }^{55}$

The ability of PRG4 to curtail the post-traumatic invasion of monocytes may be one of the mechanisms underlying the possible neuroprotective effect of PRG4. Indeed, ample evidence indicates that monocytes have a detrimental effect on neuronal survival after TBI. ${ }^{12-15}$ These inflammatory cells express TLR2/4 and CD44, ${ }^{56,57}$ and we have previously discovered that PRG4 has the ability to attenuate the chemotactic response of monocytes to the C-C motif chemokine ligand 2 (CCL2) chemokine gradient (unpublished observations). However, given an extensive degradation of PRG4 in plasma observed at 24 and $48 \mathrm{~h}$ post-TBI (see above), it is unlikely that the circulating PRG4 would have a prolonged inhibitory effect on monocyte influx into the injured brain. Although CCL2 is considered to be the major chemoattractant for monocytes, the post-traumatic upregulation of its synthesis in the brain is short lasting, ${ }^{55}$ which does not match the time course of monocyte invasion observed after TBI. ${ }^{11}$ Indeed, we found that PRG4 has no effect on post-traumatic synthesis of CCL2 in the injured cortex (data not shown). This suggests that PRG4 may have an effect on post-traumatic production of other, as yet unidentified, monocyte chemoattractants that drive the invasion of monocytes for an extended period of time after injury. ${ }^{11}$

Brain levels of endogenous TLR2/4 ligands, such as HMGB1, LGALS3, and TNC, as well as low-molecular-weight fragments of HA, which also bind to CD44, are elevated after brain injury. ${ }^{22-25}$ There is ample evidence obtained in both the in vitro systems and in vivo models of brain injury, suggesting that these endogenous TLR/CD44 ligands play important roles in increasing BBB permeability after TBI. ${ }^{53,58-60}$ Here, we demonstrate that PRG4 has a protective effect on $\mathrm{BBB}$, that is, it reduces the leakiness of the BBB observed after injury even when administered with a 4-h delay post-TBI. This suggests that PRG4 could be therapeutically effective within the time frame that is relevant to the clinical settings. The significance of this distinctive property of PRG4 cannot be overstated given that BBB dysfunction observed after TBI not only leads to neuronal death in the acute stage of injury, but may also cause progressive neurodegenerative changes in the injured brain and, consequently, neurological deficits later in life. ${ }^{61}$

The protective effect of PRG4 on the BBB appears to be, at least during the first $24 \mathrm{~h}$ after injury, associated with PRG4's ability to inhibit the post-traumatic degradation of TJ protein CLDN5. PRG4 seems unlikely to act by reversing a decrease in CLDN5 transcription, which occurs shortly after injury. Indeed, we observed a significant drop in cortical mRNA for CLDN5 at $6 \mathrm{~h}$, but not at 24 or $48 \mathrm{~h}$ post-TBI (Supplementary Fig. S2A). In comparison, cortical levels of CLDN5 protein were reduced at 6 and $24 \mathrm{~h}$ after TBI (Supplementary Fig. S2B), and PRG4 prevented these drops in CLDN5 protein expression (see Fig. 6D). The mechanisms underlying this PRG4 action remain to be determined. TBI results in a rapid upregulation of expression and/or activity of matrix metalloproteinases (MMPs), particularly MMP9, ${ }^{3}$ which is known to degrade TJ proteins, including CLDN5. ${ }^{62}$ However, PRG4 did not consistently inhibit the post-traumatic increase in cortical expression of MMP9 (data not shown). Further studies will be needed to determine the mechanisms underlying the protective effect of PRG4 on the BBB.

In summary, we demonstrated that PRG4 curtails the influx of monocytes to the injured brain, which is consistent with its ability to inhibit activation of TLR2/4 and CD44. We also showed that PRG4 restores normal BBB function after TBI by preventing the post-traumatic loss of CLDN5 and that it exerts a neuroprotective effect in neurotrauma. These findings provide support for therapeutic strategies targeting TLRs in TBI.

\section{Acknowledgments}

We thank Dr. Pierre-Olivier Couraud (INSERM U1016, Institut Cochin, Paris, France) for his generous gift of hCMEC/D3 cells. We also thank Julie Sarri and Sandrine Blondel for their technical assistance.

\section{Funding Information}

This work was supported by the NINDS (NS94440 and NS99605 to A.C.), NIAMS (AR067748 to G.D.J.), and by funds from Diane $\mathrm{N}$. Weiss and from the Department of Emergency Medicine at the Alpert Medical School of Brown University.

\section{Author Disclosure Statement}

Dr. Gregory D. Jay serves as the Chief Medical Consultant at Lubris, LLC. Both Drs. Jay and Tannin A. Schmidt have equity interests in Lubris, LLC, and they also hold licensed patents related to the use of rhPRG4. In addition, Dr. Schmidt consults for Lubris, LLC.

\section{Supplementary Material}

Supplementary Figure S1

Supplementary Figure S2

\section{References}

1. Smith, D.H., Johnson, V.E., and Stewart, W. (2013). Chronic neuropathologies of single and repetitive TBI: substrates of dementia? Nat. Rev. Neurol. 9, 211-221.

2. Ramos-Cejudo, J., Wisniewski, T., Marmar, C., Zetterberg, H., Blennow, K., de Leon, M.J., and Fossati, S. (2018). Traumatic brain injury and Alzheimer's disease: the cerebrovascular link. EBioMedicine 28, 21-30.

3. Chodobski, A., Zink, B.J., and Szmydynger-Chodobska, J. (2015). Blood-brain barrier changes in traumatic brain injury, in: The BloodBrain Barrier in Health and Disease. Volume 2, K. Dorovini-Zis (ed). CRC: Boca Raton, FL, pps. 156-183.

4. Ekdahl, C.T., Claasen, J.H., Bonde, S., Kokaia, Z., and Lindvall, O. (2003). Inflammation is detrimental for neurogenesis in adult brain. Proc. Natl. Acad. Sci. USA 100, 13632-13637.

5. Vereker, E., O'Donnell, E., and Lynch, M.A. (2000). The inhibitory effect of interleukin- $1 \beta$ on long-term potentiation is coupled with increased activity of stress-activated protein kinases. J. Neurosci. 20, 6811-6819.

6. Pickering, M., and O'Connor, J.J. (2007). Pro-inflammatory cytokines and their effects in the dentate gyrus. Prog. Brain Res. 163, 339-354.

7. Hein, A.M., Stasko, M.R., Matousek, S.B., Scott-McKean, J.J., Maier, S.F., Olschowka, J.A., Costa, A.C., and O'Banion, M.K. (2010). Sustained hippocampal IL-1 $\beta$ overexpression impairs contextual and spatial memory in transgenic mice. Brain Behav. Immun. 24, 243-253.

8. Miller, A.H., Maletic, V., and Raison, C.L. (2009). Inflammation and its discontents: the role of cytokines in the pathophysiology of major depression. Biol. Psychiatry 65, 732-741.

9. Katayama, Y., Becker, D.P., Tamura, T., and Hovda, D.A. (1990). Massive increases in extracellular potassium and the indiscriminate release of glutamate following concussive brain injury. J. Neurosurg. 73, 889-900 
10. Koizumi, H., Fujisawa, H., Ito, H., Maekawa, T., Di, X., and Bullock, R. (1997). Effects of mild hypothermia on cerebral blood flowindependent changes in cortical extracellular levels of amino acids following contusion trauma in the rat. Brain Res. 747, 304-312.

11. Gyoneva, S., and Ransohoff, R.M. (2015). Inflammatory reaction after traumatic brain injury: therapeutic potential of targeting cellcell communication by chemokines. Trends Pharmacol. Sci. 36, 471-480.

12. Hsieh, C.L., Niemi, E.C., Wang, S.H., Lee, C.C., Bingham, D., Zhang, J., Cozen, M.L., Charo, I., Huang, E.J., Liu, J., and Nakamura, M.C. (2014). CCR2 deficiency impairs macrophage infiltration and improves cognitive function after traumatic brain injury. J. Neurotrauma 31,1677-1688.

13. Gyoneva, S., Kim, D., Katsumoto, A., Kokiko-Cochran, O.N., Lamb, B.T., and Ransohoff, R.M. (2015). Ccr2 deletion dissociates cavity size and tau pathology after mild traumatic brain injury. J. Neuroinflammation $12,228$.

14. Morganti, J.M., Jopson, T.D., Liu, S., Riparip, L.K., Guandique, C.K., Gupta, N., Ferguson, A.R., and Rosi, S. (2015). CCR2 antagonism alters brain macrophage polarization and ameliorates cognitive dysfunction induced by traumatic brain injury. J. Neurosci. 35, 748-760.

15. Makinde, H.M., Cuda, C.M., Just, T.B., Perlman, H.R., and Schwulst, S.J. (2017). Nonclassical monocytes mediate secondary injury, neurocognitive outcome, and neutrophil infiltration after traumatic brain injury. J. Immunol. 199, 3583-3591.

16. Ertürk, A., Mentz, S., Stout, E.E., Hedehus, M., Dominguez, S.L., Neumaier, L., Krammer, F., Llovera, G., Srinivasan, K., Hansen, D.V., Liesz, A., Scearce-Levie, K.A., and Sheng, M. (2016). Interfering with the chronic immune response rescues chronic degeneration after traumatic brain injury. J. Neurosci. 36, 9962-9975.

17. Ramlackhansingh, A.F., Brooks, D.J., Greenwood, R.J., Bose, S.K., Turkheimer, F.E., Kinnunen, K.M., Gentleman, S., Heckemann, R.A., Gunanayagam, K., Gelosa, G., and Sharp, D.J. (2011). Inflammation after trauma: microglial activation and traumatic brain injury. Ann. Neurol. 70, 374-383.

18. Johnson, V.E., Stewart, J.E., Begbie, F.D., Trojanowski, J.Q., Smith, D.H., and Stewart, W. (2013). Inflammation and white matter degeneration persist for years after a single traumatic brain injury. Brain $136,28-42$.

19. Perry, V.H., Nicoll, J.A., and Holmes, C. (2010). Microglia in neurodegenerative disease. Nat. Rev. Neurol. 6, 193-201.

20. Hickman, S., Izzy, S., Sen, P., Morsett, L., and El Khoury, J. (2018). Microglia in neurodegeneration. Nat. Neurosci. 21, 1359-1369.

21. Yu, L., Wang, L., and Chen, S. (2010). Endogenous toll-like receptor ligands and their biological significance. J. Cell. Mol. Med. 14, 2592-2603.

22. Laird, M.D., Shields, J.S., Sukumari-Ramesh, S., Kimbler, D.E., Fessler, R.D., Shakir, B., Youssef, P., Yanasak, N., Vender, J.R., and Dhandapani, K.M. (2014). High mobility group box protein-1 promotes cerebral edema after traumatic brain injury via activation of toll-like receptor 4. Glia 62, 26-38.

23. Yip, P.K., Carrillo-Jimenez, A., King, P., Vilalta, A., Nomura, K., Chau, C.C., Egerton, A.M., Liu, Z.H., Shetty, A.J., Tremoleda, J.L., Davies, M., Deierborg, T., Priestley, J.V., Brown, G.C., MichaelTitus, A.T., Venero, J.L., and Burguillos, M.A. (2017). Galectin-3 released in response to traumatic brain injury acts as an alarmin orchestrating brain immune response and promoting neurodegeneration. Sci. Rep. 7, 41689.

24. Laywell, E.D., Dörries, U., Bartsch, U., Faissner, A., Schachner, M., and Steindler, D.A. (1992). Enhanced expression of the developmentally regulated extracellular matrix molecule tenascin following adult brain injury. Proc. Natl. Acad. Sci. U. S. A. 89, 2634-2638.

25. Al'Qteishat, A., Gaffney, J., Krupinski, J., Rubio, F., West, D., Kumar, S., Kumar, P., Mitsios, N., and Slevin, M. (2006). Changes in hyaluronan production and metabolism following ischaemic stroke in man. Brain 129, 2158-2176.

26. Jay, G.D., and Waller, K.A. (2014). The biology of lubricin: near frictionless joint motion. Matrix Biol. 39, 17-24.

27. Elsaid, K.A., Zhang, L., Shaman, Z., Patel, C., Schmidt, T.A., and Jay, G.D. (2015). The impact of early intra-articular administration of interleukin-1 receptor antagonist on lubricin metabolism and cartilage degeneration in an anterior cruciate ligament transection model. Osteoarthritis Cartilage 23, 114-121.

28. Qadri, M., Jay, G.D., Zhang, L.X., Wong, W., Reginato, A.M., Sun, C., Schmidt, T.A., and Elsaid, K.A. (2018). Recombinant human proteoglycan-4 reduces phagocytosis of urate crystals and downstream nuclear factor kappa B and inflammasome activation and production of cytokines and chemokines in human and murine macrophages. Arthritis Res. Ther. 20, 192.

29. Rhee, D.K., Marcelino, J., Baker, M., Gong, Y., Smits, P., Lefebvre, V., Jay, G.D., Stewart, M., Wang, H., Warman, M.L., and Carpten, J.D. (2005). The secreted glycoprotein lubricin protects cartilage surfaces and inhibits synovial cell overgrowth. J. Clin. Invest. 115, 622-631.

30. Aninwene, G.E. II, Abadian, P.N., Ravi, V., Taylor, E.N., Hall, D.M., Mei, A., Jay, G.D., Goluch, E.D., and Webster, T.J. (2015). Lubricin: a novel means to decrease bacterial adhesion and proliferation. J. Biomed. Mater. Res. A 103, 451-462.

31. Alquraini, A., Garguilo, S., D’Souza, G., Zhang, L.X., Schmidt, T.A., Jay, G.D., and Elsaid, K.A. (2015). The interaction of lubricin/ proteoglycan 4 (PRG4) with toll-like receptors 2 and 4: an antiinflammatory role of PRG4 in synovial fluid. Arthritis Res. Ther. 17, 353.

32. Richendrfer, H.A., Levy, M.M., Elsaid, K.A., Schmidt, T.A., Zhang, L., Cabezas, R., and Jay, G.D. (2020). Recombinant human proteoglycan-4 mediates Interleukin- 6 response in both human and mouse endothelial cells induced into a sepsis phenotype. Crit. Care Explor. 2, e0126.

33. Al-Sharif, A., Jamal, M., Zhang, L.X., Larson, K., Schmidt, T.A., Jay, G.D., and Elsaid, K.A. (2015). Lubricin/proteoglycan 4 binding to CD44 receptor: a mechanism of the suppression of proinflammatory cytokine-induced synoviocyte proliferation by lubricin. Arthritis Rheumatol. 67, 1503-1513.

34. Sarkar, A., Chanda, A., Regmi, S.C., Karve, K., Deng, L., Jay, G.D., Jirik, F.R., Schmidt, T.A., and Bonni, S. (2019). Recombinant human PRG4 (rhPRG4) suppresses breast cancer cell invasion by inhibiting TGF $\beta$-hyaluronan-CD44 signalling pathway. PLoS One 14, e0219697.

35. Puré, E., and Cuff, C.A. (2001). A crucial role for CD44 in inflammation. Trends Mol. Med. 7, 213-221.

36. Rayahin, J.E., Buhrman, J.S., Zhang, Y., Koh, T.J., and Gemeinhart, R.A. (2015). High and low molecular weight hyaluronic acid differentially influence macrophage activation. ACS Biomater. Sci. Eng. 1, 481-493.

37. Weksler, B., Romero, I.A., and Couraud, P.O. (2013). The hCMEC/D3 cell line as a model of the human blood brain barrier. Fluids Barriers CNS 10, 16.

38. Szmydynger-Chodobska, J., Fox, L.M., Lynch, K.M., Zink, B.J., and Chodobski, A. (2010). Vasopressin amplifies the production of proinflammatory mediators in traumatic brain injury. J. Neurotrauma 27, 1449-1461.

39. Molino, Y., Jabès, F., Lacassagne, E., Gaudin, N., and Khrestchatisky, M. (2014). Setting-up an in vitro model of rat blood-brain barrier (BBB): a focus on BBB impermeability and receptor-mediated transport. J. Vis. Exp. 88, e51278.

40. Strazielle, N., and Ghersi-Egea, J.F. (1999). Demonstration of a coupled metabolism-efflux process at the choroid plexus as a mechanism of brain protection toward xenobiotics. J. Neurosci. 19, 6275-6289.

41. Pardridge, W.M., Kang, Y.S., Buciak, J.L., and Yang, J. (1995). Human insulin receptor monoclonal antibody undergoes high affinity binding to human brain capillaries in vitro and rapid transcytosis through the blood-brain barrier in vivo in the primate. Pharm. Res. 12, 807-816.

42. Paxinos, G., and Watson, C. (2009). The Rat Brain in Stereotaxic Coordinates. Compact sixth edition, Academic: Amsterdam.

43. Duperray, A., Barbe, D., Raguenez, G., Weksler, B.B., Romero, I.A., Couraud, P.O., Perron, H., and Marche, P.N. (2015). Inflammatory response of endothelial cells to a human endogenous retrovirus associated with multiple sclerosis is mediated by TLR4. Int. Immunol. 27, 545-553.

44. Libermann, T.A., and Baltimore, D. (1990). Activation of interleukin6 gene expression through the NF- $\kappa \mathrm{B}$ transcription factor. Mol. Cell. Biol. 10, 2327-2334.

45. Beinke, S., and Ley, S.C. (2004). Functions of NF- $\kappa$ B 1 and NF- $\kappa$ B2 in immune cell biology. Biochem. J. 382, 393-409.

46. Fiebich, B.L., Batista, C.R.A., Saliba, S.W., Yousif, N.M., and de Oliveira, A.C.P. (2018). Role of microglia TLRs in neurodegeneration. Front. Cell. Neurosci. 12, 329.

47. Dzwonek, J., and Wilczynski, G.M. (2015). CD44: molecular interactions, signaling and functions in the nervous system. Front. Cell. Neurosci. 9, 175 . 
48. NCBI Reference Sequence: NP_005798.3. proteoglycan 4 isoform A preproprotein [Homo sapiens]. www.ncbi.nlm.nih.gov/protein/NP 005798.3 (Last accessed September 22, 2020).

49. Weigand, S., Herting, F., Maisel, D., Nopora, A., Voss, E., Schaab, C., Klammer, M., and Tebbe, A. (2012). Global quantitative phosphoproteome analysis of human tumor xenografts treated with a CD44 antagonist. Cancer Res. 72, 4329-4339.

50. Greene, C., Hanley, N., and Campbell, M. (2019). Claudin-5: gatekeeper of neurological function. Fluids Barriers CNS 16, 3.

51. Thorson, C., Galicia, K., Burleson, A., Bouchard, O., Hoppensteadt, D., Fareed, J., and Hopkinson, W. (2019). Matrix metalloproteinases and their inhibitors and proteoglycan 4 in patients undergoing total joint arthroplasty. Clin. Appl. Thromb. Hemost. 25, 1076029619828113.

52. Singh, A.K., and Jiang, Y. (2004). How does peripheral lipopolysaccharide induce gene expression in the brain of rats? Toxicology 201, 197-207.

53. Al-Ahmad, A.J., Patel, R., Palecek, S.P., and Shusta, E.V. (2019). Hyaluronan impairs the barrier integrity of brain microvascular endothelial cells through a CD44-dependent pathway. J. Cereb. Blood Flow Metab. 39, 1759-1775.

54. Zhou, H., Andonegui, G., Wong, C.H., and Kubes, P. (2009). Role of endothelial TLR4 for neutrophil recruitment into central nervous system microvessels in systemic inflammation. J. Immunol. 183 5244-5250.

55. Szmydynger-Chodobska, J., Shan, R., Thomasian, N., and Chodobski, A. (2016). The involvement of pial microvessels in leukocyte invasion after mild traumatic brain injury. PLoS One 11, e0167677.

56. Sabroe, I., Jones, E.C., Usher, L.R., Whyte, M.K., and Dower, S.K. (2002). Toll-like receptor (TLR) 2 and TLR4 in human peripheral blood granulocytes: a critical role for monocytes in leukocyte lipopolysaccharide responses. J. Immunol. 168, 4701-4710.

57. Gee, K., Lim, W., Ma, W., Nandan, D., Diaz-Mitoma, F., Kozlowski, M., and Kumar, A. (2002). Differential regulation of CD44 expression by lipopolysaccharide (LPS) and TNF- $\alpha$ in human monocytic cells: distinct involvement of c-Jun N-terminal kinase in LPS-induced CD44 expression. J. Immunol. 169, 5660-5672.
58. Zhang, J., Takahashi, H.K., Liu, K., Wake, H., Liu, R., Maruo, T., Date, I., Yoshino, T., Ohtsuka, A., Mori, S., and Nishibori, M. (2011). Anti-high mobility group box-1 monoclonal antibody protects the blood-brain barrier from ischemia-induced disruption in rats. Stroke 42, 1420-1428.

59. Okuma, Y., Liu, K., Wake, H., Zhang, J., Maruo, T., Date, I., Yoshino, T., Ohtsuka, A., Otani, N., Tomura, S., Shima, K., Yamamoto, Y., Yamamoto, H., Takahashi, H.K., Mori, S., and Nishibori, M. (2012) Anti-high mobility group box-1 antibody therapy for traumatic brain injury. Ann. Neurol. 72, 373-384.

60. Fujimoto, M., Shiba, M., Kawakita, F., Liu, L., Shimojo, N., ImanakaYoshida, K., Yoshida, T., and Suzuki, H. (2016). Deficiency of tenascin- $\mathrm{C}$ and attenuation of blood-brain barrier disruption following experimental subarachnoid hemorrhage in mice. J. Neurosurg. 124, 1693-1702.

61. Sandsmark, D.K., Bashir, A., Wellington, C.L., and Diaz-Arrastia, R (2019). Cerebral microvascular injury: a potentially treatable endophenotype of traumatic brain injury-induced neurodegeneration. Neuron 103, 367-379.

62. Yang, Y., Estrada, E.Y., Thompson, J.F., Liu, W., and Rosenberg, G.A. (2007). Matrix metalloproteinase-mediated disruption of tight junction proteins in cerebral vessels is reversed by synthetic matrix metalloproteinase inhibitor in focal ischemia in rat. J. Cereb. Blood Flow Metab. 27, 697-709.

Address correspondence to:

Adam Chodobski, PhD

Department of Emergency Medicine Alpert Medical School of Brown University

Coro Center West, Room 112

1 Hoppin Street

Providence, RI 02903

USA

E-mail: adam_chodobski@brown.edu 